NBSIR 81-2353

\title{
Documentation of Program for Determination of Conduction Transfer Functions
}

U.S. DEPARTMENT OF COMMERCE

National Bureau of Standards

National Engineering Laboratory

Center for Building Technology

Washington, DC 20234

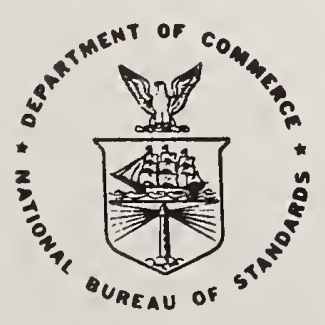

U.S. DEPARTMENT OF COMMERCE

NATIONAL BUREAU OF STANDARDS 
NBSIR $81-2353$

DOCUMENTATION OF PROGRAM FOR DETERMINATION OF CONDUCTION TRANSFER FUNCTIONS

B. A. Peavy

U.S. DEPARTMENT OF COMMERCE National Bureau of Standards National Engineering Laboratory Center for Building Technology

Washington, DC 20234

November 1981

U.S. DEPARTMENT OF COMMERCE, Malcolm Baldrige, Secretary NATIONAL BUREAU OF STANDARDS, Ernest Ambler, Director 


\section{DOCUMENTATION OF PROGRAM FOR DETERMINATION OF HEAT \\ CONDUCTION TRANSFER FUNCTIONS}

by

\section{B.A. Peavy}

\section{ABSTRACT}

Conduction transfer functions are used to predict the time-dependent onedimensional conduction heat transfer at surfaces of single- or multi-layer building constructions based on heat flux and temperature history at each surface. By the use of conduction transfer functions, heat transfer problems employing non-linear boundary conditions such as thermal radiation and timedependent changes in the surface film resistances can be solved.

Because conduction transfer functions are analtyically derived with an initial time condition of zero temperature potential throughout the solid materials, it becomes necessary to initialize the computation by including exposure to a number of outdoor weather cycles such that satisfactory initial conditions of temperature and heat flux exist at the inside and outside surfaces.

The program is set up for the use of 1-, 2-, or 3-hour time intervals, depending on the thickness of the building construction. The program allows for the combination of two building constructions, e.g., the parallel heat flow paths found in wood-frame walls.

Keywords: conduction heat transfer; conduction transfer functions; initialization of heat transfer problem; parallel heat flow; response factors; thick building construction. 


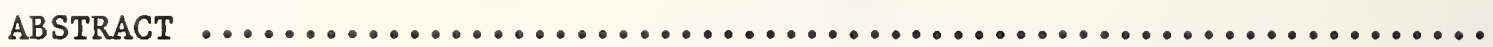

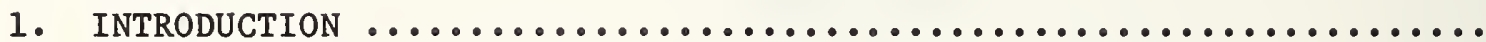

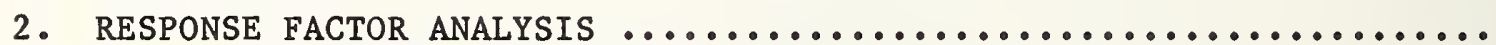

3. CONDUCTION TRANSFER FUNCTIONS ........................

4. INITIALIZATION OF SURFACE TEMPERATURES AND HEAT FLUXES $\ldots \ldots \ldots \ldots \ldots$

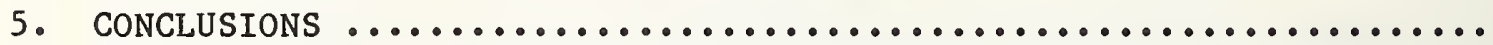

6. DESCRIPTION OF SUBROUTINES FOR DETERMINING CONDUCTION TRANSFER FUNCTIONS

6.1 SUBROUTINE PC $\ldots \ldots \ldots \ldots \ldots \ldots \ldots \ldots \ldots \ldots \ldots \ldots \ldots \ldots \ldots \ldots \ldots \ldots \ldots \ldots \ldots \ldots \ldots \ldots \ldots$

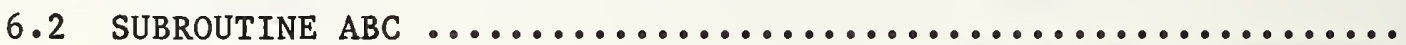

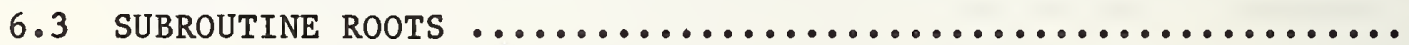

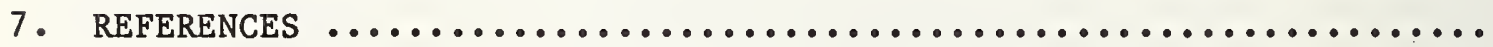

APPENDIX

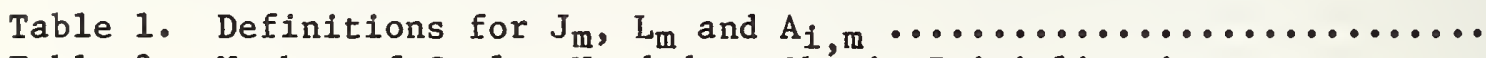

\section{LIST OF FIGURES}

Figure 1. Cross section through an n-layer building construction .....

Figure 2. Heat flux necessary to attain triangular temperature

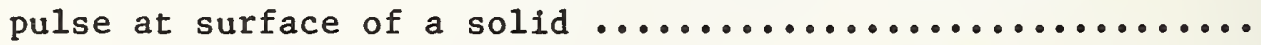

Figure 3. Set of overlapping triangular temperature pulses ......... 


\section{INTRODUCTION}

To evaluate the dynamic performance of a building, it is necessary to include calculations for the conduction heat transfer through all the components of the building envelope.

Conduction transfer functions are used to predict the time-dependent onedimensional conduction heat transfer at surfaces of single or multi-layer building constructions based on the heat flux temperature history at each surface. For example, the heat flux values at time $t$ and at the outside and inside surfaces of a particular construction are [1]:

$$
\begin{aligned}
& Q_{0, t}=\sum_{m=1}^{k} S_{m} Q_{0, t-m}+\sum_{n=1}^{1}\left(Y_{n, k} T_{i, t-n+1}-Z_{n, k} T_{0, t-n+1}\right) \\
& Q_{i, t}=\sum_{m=1}^{k} S_{m} Q_{i, t-m}+\sum_{n=1}^{1}\left(X_{n, k} T_{i, t-n+1}-Y_{n, k} T_{0, t-n+1)}\right)
\end{aligned}
$$

where $X_{n, k}, Y_{n, k}$, and $Z_{n, k}$ are $k$-th order conduction transfer functions, $S_{m}$ are coefficients of past heat flux history, and $T_{i}$ and $T_{0}$ are the inside and outside temperatures for the present and past time intervals. If surface film resistances are defined as constants at the surfaces, $T_{i}$ and $T_{0}$ are temperatures of the ambient air near the respective surfaces. If the surface film resistances are set equal to zero, $\mathrm{T}_{i}$ and $\mathrm{T}_{0}$ are surface temperatures, and it is therefore possible by use of appropriate heat balances at the surfaces to employ non-linear boundary conditions, such as thermal radiation and timedependent changes in the surface film resistances.

Conduction transfer functions of zeroth order are thermal response factors and are calculated by the program subroutine PC (see appendix) using the methodology outlined in reference [2]. Conduction transfer functions of higher order are determined in the same subroutine using the methodology outlined in reference [1]. The required thermal and physical properties of each building construction are input as layer-by-layer data by the user in a format as shown by the comment card listing for subroutine PC. A maximum of seven layers is possible excluding the outside and inside surface film thermal resistances when used. Necessary properties for each layer are thickness, thermal conductivity, density, specific heat, and air space or surface film thermal resistance when applicable. A set of conduction transfer functions is then generated.

The output for computation purposes is for each building construction, $1 \leq \mathrm{IR} \leq 20$

a) conduction transfer functions $X(I R, N), Y(I R, N), Z(I R, N) 1 \leq N \leq 20$

b) coefficients of past heat flux history $S(I R, M) 0 \leq M \leq 5$

c) defined building construction conductance U(IR) 
d) integers: $\operatorname{NTR}(\operatorname{IR}, 1)=\mathrm{L}, \operatorname{NTR}(\operatorname{IR}, 2)=\mathrm{K}, \operatorname{NTR}(\operatorname{IR}, 3)=\mathrm{J}$

$L$ is the number of conduction transfer functions

$\mathrm{K}$ is the number of heat flux coefficients, and also the order of the conduction transfer functions

$\mathrm{J}$ is the time intervals, 1,2 , or 3 hours.

The program subroutine PC allows for the combination of two building constructions, such as parallel heat flow paths as found in wood-frame walls with both cavity and wood stud construction. Both constructions are entered with the lighter (smaller weight per unit are) construction entered first and the percent area of both inserted as shown in the examples.

For thick building constructions (usually thicknesses greater than 3 feet), a 1-hour time interval is not a sufficiently large value for allowing the effects of the temperature history on one surface to be transmitted to the heat flux on the other surface. For this reason time intervals of 2 and 3 hours are used for the thicker constructions. Algorithms for the use of 1-, 2-, and 3-hour time intervals in the determination of heat flux quantities are contained in subroutines $P I, P R$ an $P Q$. These subroutines are used to initialize the surface temperatures and heat fluxes for the various constructions. Subroutine $P Q$ performs the summation on known past surface temperatures and heat fluxes, namely

$$
\begin{aligned}
& W_{0, t}=\sum_{m=1}^{k} S_{m} Q_{0, t-m}+\sum_{n=2}^{1}\left(Y_{n, k} T_{1, t-n+1}-Z_{n, k} T_{o, t-n+1}\right) \\
& W_{i, t}=\sum_{m=1}^{k} S_{m} Q_{1, t-m}+\sum_{n=2}^{1}\left(X_{n, k} T_{1, t-n+1}-Y_{n, k} T_{o, t-n+1}\right)
\end{aligned}
$$

Also, it is assumed for each time interval:

$$
\begin{aligned}
& Q_{0, t}=H_{0}\left[G(t)-T_{0, t}\right] \\
& Q_{i, t}=H_{i}\left[T_{i, t}-T_{a} \cdot\right]
\end{aligned}
$$

where $G(t)$ is temperature variation of the outdoor temperature and $T_{a}$ is the indoor temperature. Setting (5) equal to (1), and (6) equal to (2), two simultaneous equations are derived from which values for the surface temperatures $T_{0, t}$ and $T_{1, t}$ can be found, and the heat fluxes are computed from ( 1 ) and (2), or (5) and (6). For each diurnal (24-hour) cycle and each building construction, the sums of the outside and inside heat fluxes and the surface temperatures are printed. When the sums of the heat fluxes become closely equal to each other and change very little from the previous cycles, it can be assumed that the initialization process has been completed for a particular building construction. 


\section{RESPONSE FACTOR ANALYSIS}

For one-dimensional heat flow in an individual layer of one or more parallel layers of a building construction (see figure 1), the partial differential equation for conduction heat flow is given by

$$
\frac{\partial^{2} v_{m}}{\partial x^{2}}=\frac{1}{\alpha_{m}} \frac{\partial v_{m}}{\partial t}
$$

where $v_{m}$ is the temperature potential with respect to a datum plane temperature, $x$ is a dimension along which heat is flowing, $\alpha_{m}$ is the thermal diffusivity of the layer material, and $t$ is the time. For continuity of temperature and heat flow at the interface of the layers, perfect contact is assumed, so that at $x=b_{m}$ the following conditions apply

$$
\begin{aligned}
& \mathrm{v}_{\mathrm{m}-1}=\mathrm{v}_{\mathrm{m}} \\
& \mathrm{K}_{\mathrm{m}-1} \frac{\mathrm{dv}_{\mathrm{m}-1}}{\mathrm{dx}}=\mathrm{K}_{\mathrm{m}} \frac{\mathrm{dv}_{\mathrm{m}}}{\mathrm{dx}}
\end{aligned}
$$

where $\mathrm{K}$ is the thermal conductivity of the respective layer material. At the exposed surfaces $x=0$ and $x=b_{n}$, the heat fluxes are assumed proportional to the temperature difference between the fluid (air, gas or liquid) and the surfaces, and are represented by the temperature relationships

$$
-R_{0} K_{1} \quad \frac{d v_{1}}{d x}=f(t)-v_{1} \quad \text { at } x=0
$$

and

$$
-R_{i} K_{n} \frac{d v_{n}}{d x}=v_{n}-g(t) \quad \text { at } x=b_{n}
$$

where $R_{0}$ and $R_{i}$ are the surface film resistances, and $f(t)$ and $g(t)$ are the fluid temperatures as a function of time. When $R_{0}$ and/or $R_{1}$ is zero, the time temperature function(s) $f(t)$ and/or $g(t)$ represent temperature(s) at the respective surface(s). Applying the Laplace transform to (7), a solution for the transform of the temperature becomes

$$
\bar{v}_{m}=A_{m} e^{q_{m}\left(x-b_{m}\right)}+B_{m} e^{-q_{m}\left(x-b_{m}\right)}
$$

where $\mathrm{p}$ is the Laplace parameter, $\mathrm{q}_{\mathrm{m}}^{2}=\mathrm{p} / \alpha_{\mathrm{m}}$, and $\mathrm{A}_{\mathrm{m}}$ and $\mathrm{B}_{\mathrm{m}}$ are constants to be determined from conditions at the two surfaces of an individual layer. Applying the Laplace transform to (8), (9), (10), an (11), expressions for the transforms of the temperatures at the exposed surfaces of layer 1 and layer $n$ (figure 1) are given by

$\bar{v}_{1}=\frac{\bar{f}(p)}{W}\left[P_{1}+Q_{1}+v_{2} \sqrt{p}\left(S_{1}+T_{1}\right)\right]+\frac{\overline{H g}(p)}{W}\left[\sinh \times \sqrt{p} / \alpha_{1}+V_{1} \sqrt{p} \cosh \times \sqrt{p} / \bar{\alpha}_{1}\right]$ 


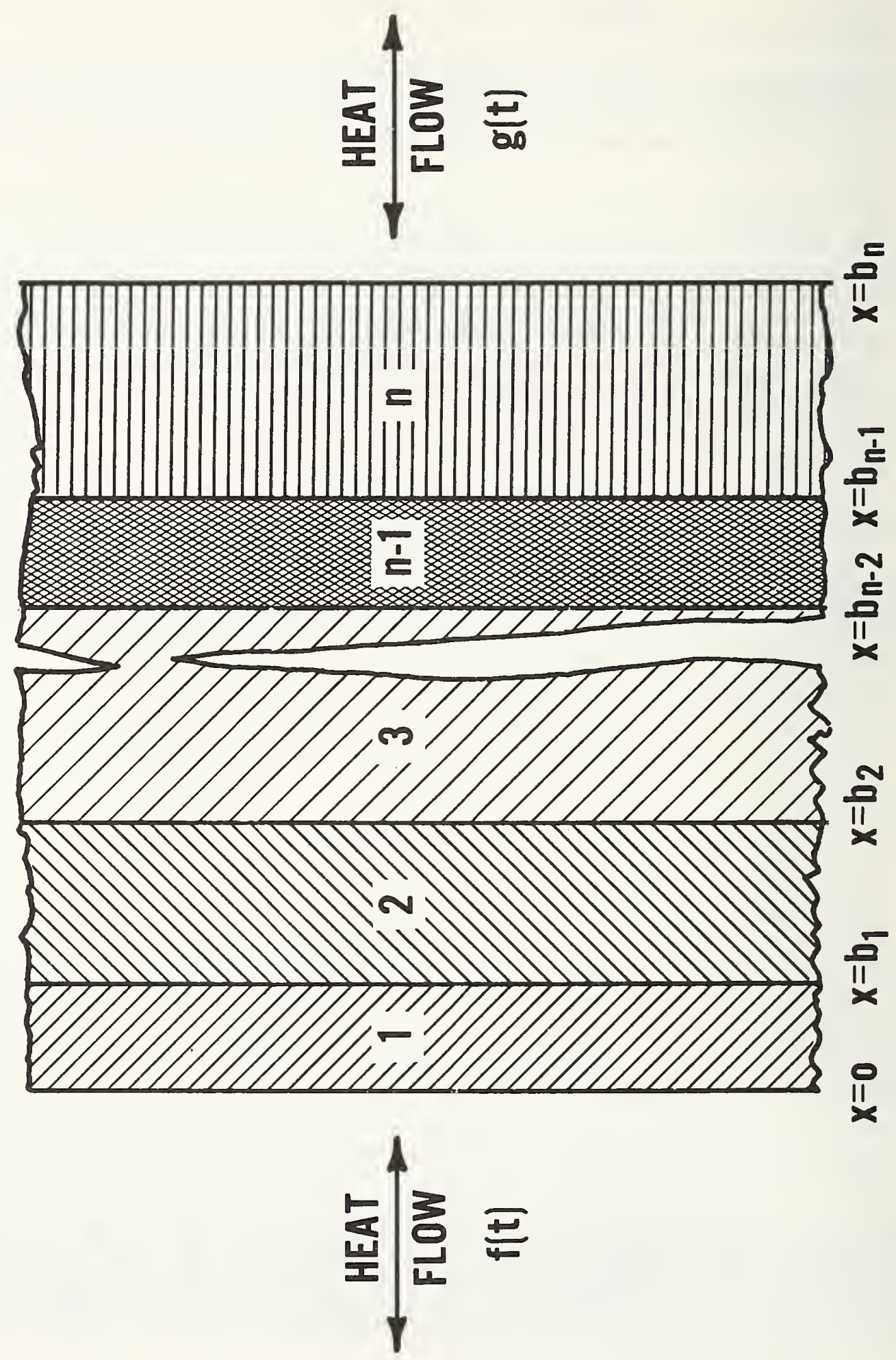

Figure 1. Cross section through an n-layer building construction 


$$
\begin{aligned}
\bar{v}_{n} & =\frac{\bar{G}(p)}{W}\left[\sinh \left(b_{n}-x\right) \sqrt{p / \alpha_{n}}+v_{2} \sqrt{p} \cosh \left(b_{n}-x\right) \sqrt{p / \alpha_{n}}\right] \\
& +\frac{\bar{g}(p)}{W}\left[P_{2}+Q_{2}+v_{1} \sqrt{p}\left(s_{2}-T_{2}\right)\right]
\end{aligned}
$$

where

$$
\begin{aligned}
\mathrm{P}_{1} & =\sum J_{\mathrm{m}} \sinh \left[\left(\mathrm{N}_{\mathrm{m}}-\mathrm{x} / \sqrt{\alpha_{1}}\right) \sqrt{\mathrm{p}}\right] \\
\mathrm{S}_{1} & =\sum \mathrm{J}_{\mathrm{m}} \cosh \left[\left(\mathrm{N}_{\mathrm{m}}-\mathrm{x} / \sqrt{\alpha_{1}}\right) \sqrt{\mathrm{p}}\right] \\
\mathrm{P}_{2} & =\sum J_{\mathrm{m}} \sinh \left[\left(\mathrm{N}_{\mathrm{m}}-\left(\mathrm{b}_{\mathrm{n}}-\mathrm{x}\right) / \sqrt{\alpha_{\mathrm{n}}}\right) \sqrt{\mathrm{p}}\right] \\
\mathrm{S}_{2} & =\sum \mathrm{J}_{\mathrm{m}} \cosh \left[\left(\mathrm{N}_{\mathrm{m}}-\left(\mathrm{b}_{\mathrm{n}}-\mathrm{x}\right) / \sqrt{\alpha_{\mathrm{n}}}\right) \sqrt{\mathrm{p}}\right] \\
\mathrm{P} & =\sum \mathrm{J}_{\mathrm{m}} \sinh \mathrm{N}_{\mathrm{m}} \sqrt{\mathrm{p}} \\
\mathrm{S} & =\sum \mathrm{J}_{\mathrm{m}} \cosh \mathrm{N}_{\mathrm{m}} \sqrt{\mathrm{p}}
\end{aligned}
$$$$
\mathrm{Q}_{1}=\sum \mathrm{L}_{\mathrm{m}} \sinh \left[\left(\mathrm{E}_{\mathrm{m}}+\mathrm{x} / \sqrt{\alpha_{1}}\right) \sqrt{\mathrm{p}}\right]
$$$$
\mathrm{T}_{1}=\Sigma \mathrm{L}_{\mathrm{m}} \cosh \left[\left(\mathrm{E}_{\mathrm{m}}+\mathrm{x} \sqrt{\alpha_{1}}\right) \sqrt{\mathrm{p}}\right]
$$$$
\mathrm{Q}_{2}=\sum \mathrm{L}_{\mathrm{m}} \sinh \left[\left(\mathrm{E}_{\mathrm{m}}-\left(\mathrm{b}_{\mathrm{n}}-\mathrm{x}\right) / \sqrt{\alpha_{\mathrm{n}}}\right) \sqrt{\mathrm{p}}\right]
$$$$
\mathrm{T}_{2}=\Sigma \mathrm{L}_{\mathrm{m}} \cosh \left[\left(\mathrm{E}_{\mathrm{m}}-\left(\mathrm{b}_{\mathrm{n}}-\mathrm{x}\right) / \sqrt{\alpha_{\mathrm{n}}}\right) \sqrt{\mathrm{p}}\right]
$$$$
\mathrm{Q}=\Sigma \mathrm{L}_{\mathrm{m}} \sinh \mathrm{E}_{\mathrm{m}} \sqrt{\mathrm{p}}
$$$$
T=\Sigma L_{m} \cosh E_{m} \sqrt{p}
$$

(The above summations are over $m=1$ to $2^{n-2}$, $n$ being the number of layers.)

$$
\begin{array}{ll}
\sigma_{m}=\frac{K_{m+1}}{K_{m}} \sqrt{\alpha_{m}} / \alpha_{m+1} & k_{m}=\left(1-\sigma_{m}\right) /\left(1+\sigma_{m}\right) \\
G=2^{n-1} /\left(1+\sigma_{1}\right)\left(1+\sigma_{2}\right) \ldots\left(1+\sigma_{n-1}\right) & H=G \frac{K_{n}}{K_{1}} \sqrt{\alpha_{1} / \alpha_{n}} \\
V_{1}=R_{0} K_{1} / \sqrt{\alpha_{1}} & V_{2}=R_{1} K_{n} / \sqrt{\alpha_{n}} \\
N_{m}=\sum_{i=1}^{n} A_{i, m}\left(b_{1}-b_{1-1}\right) / \sqrt{\alpha_{i}}, & E_{m}=N_{m}-2 b_{1} / \sqrt{\alpha_{1}}, A_{1, m}=1 \\
\left(J_{m}, L_{m} \text { and } A_{1, m} \text { are defined in table } 1 .\right) & \\
W=P+Q+V_{1} V_{2} P(P-Q)+\sqrt{P}\left[V_{2}(S+T)+V_{1}(S-T)\right]
\end{array}
$$

The transforms of the heat flux at $x=0$ and at $x=b_{n}$ are found by differentiating (13) and (14) with respect to $x$ and multiplying by minus one and the thermal conductivity of layer 1 and $n$, respectively:

$$
\begin{aligned}
& \bar{F}_{1}=\frac{K_{L} \sqrt{p}}{W \sqrt{\alpha_{n}}}\left(\left[S-T+V_{2} \sqrt{p}(P-Q)\right] \bar{f}(p)-\overline{H g}(p)\right) \\
& \bar{F}_{n}=\frac{K_{n} \sqrt{p}}{W \sqrt{\alpha_{n}}}\left\{G \bar{f}(p)-\left[S+T+V_{1} \sqrt{p}(P-Q)\right] \bar{g}(p)\right\}
\end{aligned}
$$


Table 1. Definitions for $J_{m}, L_{m}$ and $A_{i, m}$

\begin{tabular}{|c|c|c|c|c|c|c|c|c|}
\hline $\mathrm{m}$ & $\mathrm{J}_{\mathrm{m}}$ & $\mathrm{L}_{\mathrm{m}}$ & $A_{2}, m$ & $A_{3, m}$ & $\mathrm{~A}_{4, \mathrm{~m}}$ & $A_{5, m}$ & $A_{6, m}$ & $\mathrm{~A}_{7}, \mathrm{~m}$ \\
\hline 1 & 1 & $\mathrm{k}_{1}$ & 1 & 1 & 1 & 1 & 1 & 1 \\
\hline 2 & $k_{1} k_{2}$ & $k_{2}^{1}$ & -1 & 1 & 1 & 1 & 1 & 1 \\
\hline 3 & $k_{1} k_{3}$ & $k_{3}$ & -1 & -1 & 1 & 1 & 1 & 1 \\
\hline 4 & $k_{2} k_{3}$ & $k_{1} k_{2} k_{3}$ & 1 & -1 & 1 & 1 & 1 & 1 \\
\hline 5 & $k_{1} k_{4}$ & $\mathrm{k}_{4}$ & -1 & -1 & -1 & 1 & 1 & 1 \\
\hline 6 & $k_{2} k_{4}$ & $\mathrm{k}_{1} \mathrm{k}_{2} \mathrm{k}_{4}$ & 1 & -1 & -1 & 1 & 1 & 1 \\
\hline 7 & $k_{3} k_{4}$ & $k_{1} k_{3} k_{4}$ & 1 & 1 & -1 & 1 & 1 & 1 \\
\hline 8 & $k_{1} k_{2} k_{3} k_{4}$ & $k_{2} k_{3} k_{4}$ & -1 & 1 & -1 & 1 & 1 & 1 \\
\hline 9 & $k_{4} k_{5}$ & $\mathrm{k}_{1} \mathrm{k}_{4} \mathrm{k}_{5}$ & 1 & 1 & 1 & -1 & 1 & 1 \\
\hline 10 & $k_{3} k_{5}$ & $k_{1} k_{3} k_{5}$ & 1 & 1 & -1 & -1 & 1 & 1 \\
\hline 11 & $k_{2} k_{5}$ & $k_{1} k_{2} k_{5}$ & 1 & -1 & -1 & -1 & 1 & 1 \\
\hline 12 & $k_{1} k_{5}$ & $\mathrm{k}_{5}$ & -1 & -1 & -1 & -1 & 1 & 1 \\
\hline 13 & $k_{1} k_{2} k_{3} k_{5}$ & $k_{2} k_{3} k_{5}$ & -1 & 1 & -1 & -1 & 1 & 1 \\
\hline 14 & $k_{1} k_{2} k_{4} k_{5}$ & $k_{2} k_{4} k_{5}$ & -1 & 1 & 1 & -1 & 1 & 1 \\
\hline 15 & $k_{1} k_{3} k_{4} k_{5}$ & $\mathrm{k}_{3} \mathrm{k}_{4} \mathrm{k}_{5}$ & -1 & -1 & 1 & -1 & 1 & 1 \\
\hline 16 & $k_{2} k_{3} k_{4} k_{5}$ & $k_{1} k_{2} k_{3} k_{4} k_{5}$ & 1 & -1 & 1 & -1 & 1 & 1 \\
\hline 17 & $\mathrm{k}_{5} \mathrm{k}_{6}$ & $\mathrm{k}_{1} \mathrm{k}_{5} \mathrm{k}_{6}$ & 1 & 1 & 1 & 1 & -1 & 1 \\
\hline 18 & $k_{4} k_{6}$ & $k_{1} k_{4} k_{6}$ & 1 & 1 & 1 & -1 & -1 & 1 \\
\hline 19 & $k_{3} k_{6}$ & $k_{1} k_{3} k_{6}$ & 1 & 1 & -1 & -1 & -1 & 1 \\
\hline 20 & $k_{2} k_{6}$ & $k_{1} k_{2} k_{6}$ & 1 & -1 & -1 & -1 & -1 & 1 \\
\hline 21 & $k_{1} k_{6}$ & $\mathrm{k}_{6}$ & -1 & -1 & -1 & -1 & -1 & 1 \\
\hline 22 & $k_{1} k_{2} k_{3} k_{6}$ & $k_{2} k_{3} k_{6}$ & -1 & 1 & -1 & -1 & -1 & 1 \\
\hline 23 & $k_{1} k_{2} k_{4} k_{6}$ & $k_{2} k_{4} k_{6}$ & -1 & 1 & 1 & -1 & -1 & 1 \\
\hline 24 & $k_{1} k_{2} k_{5} k_{6}$ & $k_{2} k_{5} k_{6}$ & -1 & 1 & 1 & 1 & -1 & 1 \\
\hline 25 & $k_{1} k_{3} k_{4} k_{6}$ & $k_{3} k_{4} k_{6}$ & -1 & -1 & 1 & -1 & -1 & 1 \\
\hline 26 & $k_{1} k_{3} k_{5} k_{6}$ & $k_{3} k_{5} k_{6}$ & -1 & -1 & 1 & 1 & -1 & 1 \\
\hline 27 & $k_{1} k_{4} k_{5} k_{6}$ & $k_{4} k_{5} k_{6}$ & -1 & -1 & -1 & 1 & -1 & 1 \\
\hline 28 & $k_{2} k_{3} k_{4} k_{6}$ & $k_{1} k_{2} k_{3} k_{4} k_{6}$ & 1 & -1 & 1 & -1 & -1 & 1 \\
\hline 29 & $k_{2} k_{3} k_{5} k_{6}$ & $k_{1} k_{2} k_{3} k_{5} k_{6}$ & 1 & -1 & 1 & 1 & -1 & 1 \\
\hline 30 & $k_{2} k_{4} k_{5} k_{6}$ & $k_{1} k_{2} k_{4} k_{5} k_{6}$ & 1 & -1 & -1 & 1 & -1 & 1 \\
\hline 31 & $k_{3} k_{4} k_{5} k_{6}$ & $k_{1} k_{3} k_{4} k_{5} k_{6}$ & 1 & 1 & -1 & 1 & -1 & 1 \\
\hline 32 & $k_{1} k_{2} k_{3} k_{4} k_{5} k_{6}$ & $k_{2} k_{3} k_{4} k_{5} k_{6}$ & -1 & 1 & -1 & 1 & -1 & 1 \\
\hline
\end{tabular}


The inversion of (15) and (16), as shown in reference [3], is performed by evaluating the residues at the poles of the denominator $W=0$, where $p=-\beta^{2}$ or $\sqrt{\mathrm{p}}=i \beta$, which gives the relationship

$$
\begin{aligned}
W(\beta) & =\left(1-\mathrm{V}_{1} \mathrm{~V}_{2}{ }^{2}\right) \sum J_{\mathrm{m}} \sin \mathrm{N}_{\mathrm{m}} \beta+\left(1+\mathrm{V}_{1} \mathrm{~V}_{2}{ }^{2}\right) \sum \mathrm{L}_{\mathrm{m}} \sin \mathrm{E}_{\mathrm{m}} \beta \\
& +\beta\left[\left(\mathrm{V}_{2}+\mathrm{V}_{1}\right) \sum \mathrm{J}_{\mathrm{m}} \cos \mathrm{N}_{\mathrm{m}} \beta+\left(\mathrm{V}_{2}-\mathrm{V}_{1}\right) \sum \mathrm{L}_{\mathrm{m}} \cos \mathrm{E}_{\mathrm{m}} \beta\right]=0
\end{aligned}
$$

and the differentiation of $W$ with respect to $p$ evaluated at $p=-\beta^{2}$ gives

$$
\begin{aligned}
U & =\left(1-V_{1} V_{2}{ }^{2}\right) \sum J_{m} N_{m} \cos N_{m}^{\beta}+\left(1+V_{1} V_{2} \beta^{2}\right) \sum L_{m} E_{m} \cos E_{m} \beta \\
& +\left(V_{2}+V_{1}\right)\left[\Sigma J_{m} \cos N_{m} \beta-\beta \sum J_{m} N_{m} \sin N_{m} \beta\right] \\
& +\left(V_{2}-V_{1}\right)\left[\Sigma L_{m} \cos E_{m} \beta-\beta \sum L_{m} E_{m} \sin E_{m} \beta\right] \\
& -2 \beta v_{1} V_{2}\left[\Sigma J_{m} \sin N_{m} \beta-\sum L_{m} \sin E_{m} \beta\right]
\end{aligned}
$$

where $2 i \beta \quad\left(\frac{d W}{d p}\right)_{p=-\beta}=U$

The residues at the poles $p=-\beta^{2}$ are

$$
F_{1 \beta}=-\frac{2 K_{1}}{\sqrt{\alpha_{1}}} \Sigma \sum_{U_{i}}^{\beta_{i}^{2}}\left[\bar{f}\left(-\beta_{i}^{2}\right)\left(D_{1}-V_{2} D_{2} \beta\right)-\overline{H g}\left(-\beta_{i}^{2}\right)\right] e^{-\beta_{i}^{2} t}
$$

and

$$
F_{n \beta}=-\frac{2 K_{n}}{\sqrt{\alpha_{n}}} \sum \frac{\beta_{i}^{2}}{U_{i}}\left[G \bar{f}\left(-\beta_{i}^{2}\right)-\left(D_{3}-V_{1} D_{2} \beta\right) \bar{g}\left(-\beta_{i}^{2}\right)\right] e^{-\beta_{i}^{2} t}
$$

where $B_{i}$ satisfy $W(B)=0$, and

$$
\begin{aligned}
& \mathrm{D}_{1}=\Sigma\left(J_{\mathrm{m}} \cos \mathrm{N}_{\mathrm{m}} \beta-\mathrm{L}_{\mathrm{m}} \cos \mathrm{E}_{\mathrm{m}} \beta\right), \mathrm{B}_{3}=\Sigma\left(\mathrm{J}_{\mathrm{m}} \cos \mathrm{N}_{\mathrm{m}} \beta+\mathrm{L}_{\mathrm{m}} \cos \mathrm{E}_{\mathrm{m}} \beta\right), \\
& \mathrm{D}_{2}=\Sigma\left(J_{\mathrm{m}} \sin \mathrm{N}_{\mathrm{m}} \beta-\mathrm{L}_{\mathrm{m}} \sin \mathrm{E}_{\mathrm{m}} \beta\right) .
\end{aligned}
$$

of particular concern is the evaluation of the first root of (17). This can be done expeditiously by expanding the sines and cosines in their series and considering only the first two terms, in order to obtain an initial estimate of the first root

$$
W_{B} \simeq A_{1} B-A_{2} \quad B^{3}
$$

or $B^{2}{ }_{1} \approx \mathrm{A}_{1} / \mathrm{A}_{2}$

with

$$
A_{1}=\sum\left(J_{m} N_{m}+L_{m} E_{m}\right)+\left(V_{1}+V_{2}\right) \sum J_{m}+\left(V_{2}-V_{1}\right) \Sigma L_{m}
$$


and

$$
\begin{aligned}
A_{2} & =V_{1} V_{2} \sum\left(J_{m} N_{m}-L_{m} E_{m}\right)+\frac{V_{1}+V_{2}}{2} \sum J_{m} N_{m}^{2}+\frac{V_{2}-V_{1}}{2} \sum L_{m} E_{m}^{2} \\
& +\frac{1}{6} \Sigma\left(J_{m} N_{m}^{3}+L_{m} E_{m}^{3}\right) .
\end{aligned}
$$

Next, it is expedient to define the temperature functions $f(t)$ and $g(t)$. First, these functions are defined as triangular temperature pulse functions (see figure 2), and solutions obtained for the heat flux at subsequent time intervals may, by superposition, be used as shown in equation (1). The time function is defined by:

$$
\begin{aligned}
& \begin{array}{ll}
f(t)=0 & \bar{f}(p)=0
\end{array} \\
& =t / \delta=1 / \delta p^{2} \\
& =2-t / \delta \\
& =0 \\
& =\left(1-2 e^{-p \delta}\right) / \delta p^{2} \\
& =\left(1-\mathrm{e}^{-\mathrm{p} \delta}\right)^{2} / \delta \mathrm{p}^{2}
\end{aligned}
$$

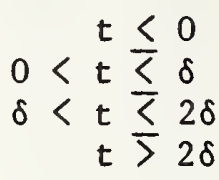

which when substituted for $\bar{f}(p)$ and $\bar{g}(p)$ in (15) and (16) gives double poles at $p=0$ (reference $3, p .78$ ). The following expressions are limits of the necessary functions of (15) and (16) for evaluating the residues at the double poles.

$$
\begin{aligned}
& \operatorname{Lim}_{\mathrm{p} \rightarrow 0} \frac{W}{\sqrt{p}}=A_{1}+A_{2} P \\
& \operatorname{Lim}_{\mathrm{p} \rightarrow 0}(S-T)+V_{2} \sqrt{p}(P-Q)=B_{1}+B_{2} P \\
& \operatorname{Lim}_{\mathrm{p} \rightarrow 0}(S+T)+V_{1} \sqrt{p}(P-Q)=C_{1}+C_{2} p
\end{aligned}
$$

$A_{1}$ and $A_{2}$ are defined following (21) and

$$
\begin{aligned}
& \mathrm{B}_{1}=\sum\left(\mathrm{J}_{\mathrm{m}}-\mathrm{L}_{\mathrm{m}}\right), \mathrm{C}_{1}=\sum\left(\mathrm{J}_{\mathrm{m}}+\mathrm{L}_{\mathrm{m}}\right) \\
& \mathrm{B}_{2}=\frac{1}{2} \sum\left(\mathrm{J}_{\mathrm{m}} \mathrm{N}_{\mathrm{m}}^{2}+\mathrm{L}_{\mathrm{m}} \mathrm{E}_{\mathrm{m}}^{2}\right)+\mathrm{V}_{1} \sum\left(\mathrm{J}_{\mathrm{m}} \mathrm{N}_{\mathrm{m}}-\mathrm{L}_{\mathrm{m}} \mathrm{E}_{\mathrm{m}}\right) \\
& \mathrm{C}_{2}=\frac{1}{2} \sum\left(\mathrm{J}_{\mathrm{m}} \mathrm{N}_{\mathrm{m}}^{2}+\mathrm{L}_{\mathrm{m}} \mathrm{E}_{\mathrm{m}}^{2}\right)+\mathrm{V}_{1} \sum\left(\mathrm{J}_{\mathrm{m}} \mathrm{N}_{\mathrm{m}}-\mathrm{L}_{\mathrm{m}} \mathrm{E}_{\mathrm{m}}\right)
\end{aligned}
$$

For the first term in (15), the residue for $0<t<\delta$ is

$$
x_{t}=\frac{K_{1}}{\delta \sqrt{\alpha_{1}}}\left(\frac{\mathrm{tB}_{1}}{\mathrm{~A}_{1}}+\frac{\mathrm{A}_{1} \mathrm{~B}_{2}-\mathrm{A}_{2} \mathrm{~B}_{1}}{\mathrm{~A}_{1}^{2}}\right)
$$


7VILM

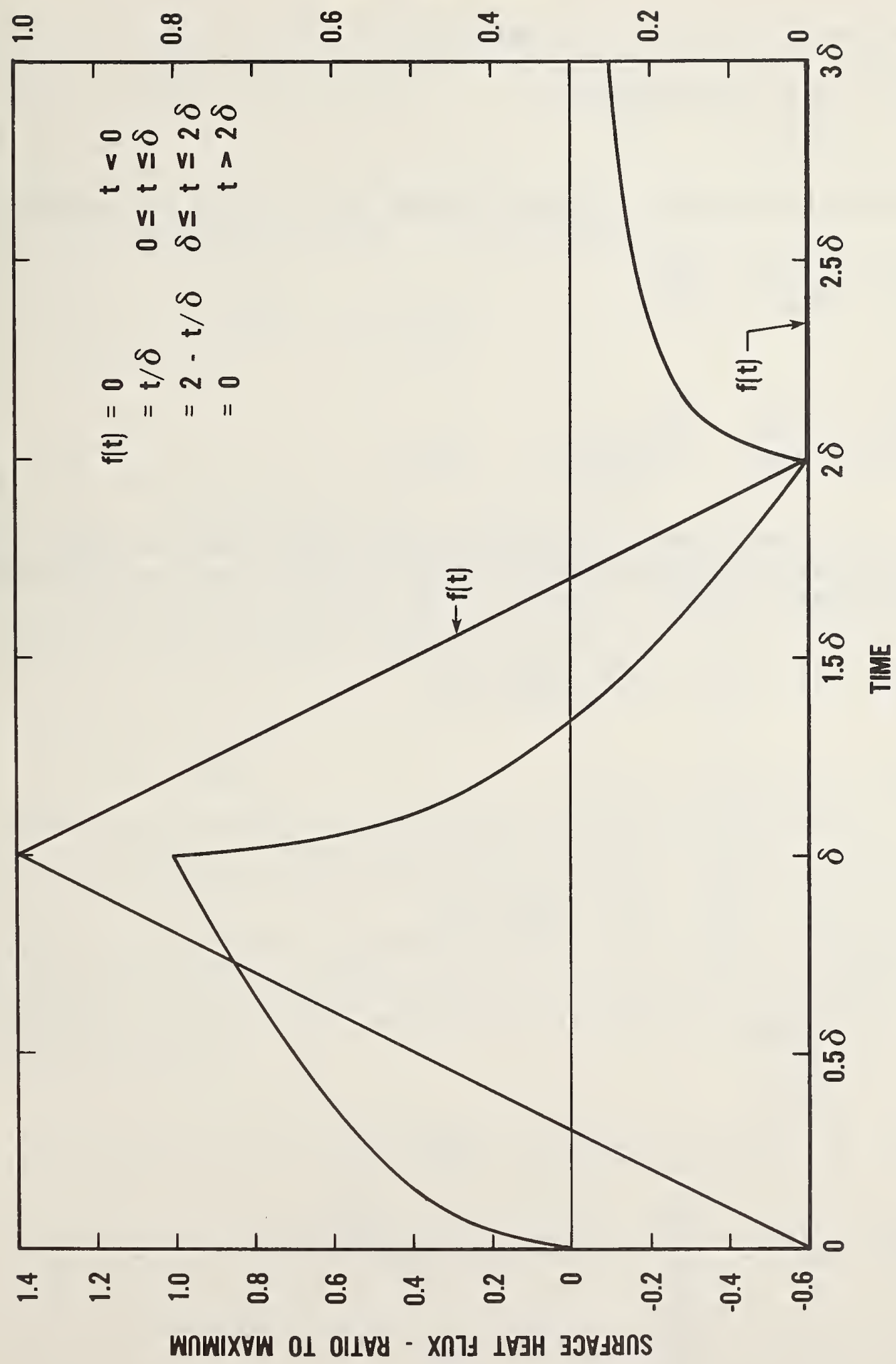

Figure 2. Heat flux necessary to attain triangular temperature pulse at surface of a solid. 
for the last term in (16), the residue is

$$
z_{t}=\frac{K_{n}}{\delta \sqrt{\alpha_{n}}}\left(\frac{t C_{1}}{A_{1}}+\frac{A_{1} C_{2}-A_{2} C_{1}}{A_{1}^{2}}\right)
$$

and for the first term in (16) and the last term in (15), the residue is

$$
Y_{t}=\frac{K_{n} G}{\delta \sqrt{\alpha_{n}}}\left(\frac{t}{A_{1}}-\frac{A_{2}}{A_{1}^{2}}\right)
$$

where

$$
\frac{K_{1} B_{1}}{A_{1} \sqrt{\alpha_{1}}}=\frac{K_{n} C_{1}}{A_{1} \sqrt{\alpha_{n}}}=\frac{K_{n} G}{A_{1} \sqrt{\alpha_{n}}}=\frac{1}{R}
$$

and $R$ is the total thermal resistance of the n-layers plus $R_{1}$ and $R_{2}$. The response factors $X_{1}, Y_{1}$ and $Z_{1}$ from (23), (24), (25), (19) and (20) evaluated at $t=\delta$, become

$$
\begin{aligned}
& \mathrm{x}_{1,0}=\overline{\mathrm{x}}_{\delta}-\frac{\mathrm{K}_{1}}{{\sqrt{\alpha_{1}}}} \Sigma\left(\mathrm{D}_{1}-\mathrm{v}_{2} \mathrm{D}_{2} \beta_{1}\right) \psi_{1} \\
& \overline{\mathrm{Y}}_{1,0}=\overline{\mathrm{Y}}_{\delta}-\frac{\mathrm{K}_{\mathrm{n}} \mathrm{G}}{\sqrt{\alpha_{\mathrm{n}}}} \Sigma\left(D_{3}\right) \psi_{1}
\end{aligned}
$$

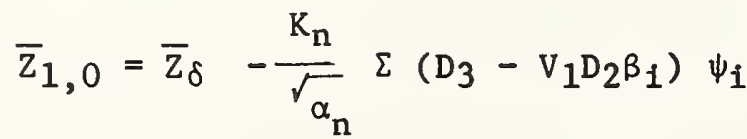

where

$$
\psi i=\frac{2 e^{-\beta_{i}^{2} \delta}}{\delta \beta_{i}^{2} U_{i}}
$$

For $\mathrm{X}_{2,0}, \mathrm{Y}_{2,0}$ and $\mathrm{Z}_{2,0}$ evaluated at $\mathrm{t}=2 \delta$,

$$
\begin{aligned}
& \mathrm{X}_{2,0}=\frac{1}{\mathrm{R}}-\mathrm{Y}_{\delta}-\frac{\mathrm{K}_{1}}{\sqrt{\alpha_{1}}} \sum\left(\mathrm{D}_{1}-\mathrm{V}_{2} \mathrm{D}_{2} \beta_{1}\right) \psi_{1}\left(e^{-\beta_{1}^{2} \delta}-2\right) \\
& \mathrm{Y}_{2,0}=\frac{1}{\mathrm{R}}-\mathrm{Y}_{\delta}-\frac{\mathrm{K}_{\mathrm{n}} G}{\sqrt{\alpha_{\mathrm{n}}}} \sum \psi_{1}\left(e^{-\beta_{1}^{2}}-2\right)
\end{aligned}
$$




$$
z_{2,0}=\frac{1}{R}-z_{\delta}-\frac{K_{n}}{\sqrt{\alpha_{n}}} \sum\left(D_{3}-v_{1} D_{2} \beta_{i}\right) \psi_{i}\left(e^{-\beta_{i}^{2} \beta}-2\right),
$$

and for $t>2 \delta$,

$$
\begin{aligned}
& x_{j, 0}=-\frac{K_{1}}{\sqrt{\alpha_{1}}} \sum\left(D_{1}-V_{2} D_{2} \beta_{i}\right) \psi_{i}\left(1-e^{-\beta_{i}^{2} \delta}\right)^{2} e^{-(j-3)_{B_{1}^{2}}^{2} \delta} \\
& Y_{j, 0}=-\frac{K_{n} G}{\sqrt{\alpha_{n}}} \sum \psi_{i}\left(1-e^{-\beta^{2} \delta}\right)^{2} e^{-(j-3) \beta_{i}^{2} \delta} \\
& z_{j, 0}=-\mathrm{K}_{\mathrm{n}} \sum\left(\mathrm{D}_{3}-\mathrm{V}_{1} \mathrm{D}_{2} \beta_{i}\right) \psi_{i}\left(1-\mathrm{e}^{-\beta_{1}^{2} \delta}\right)^{2} e^{-(j-3)} \beta_{i}^{2} \delta
\end{aligned}
$$

Equations $7, \mathrm{~m}=1,2, \ldots \mathrm{n}$, are linear partial differential equations which, for the continuity conditions ( 8 ) and (9), and the boundary conditions (10), (11), and (22), give solutions for the heat flux at discrete time, $t=j \delta$, by equations 26,27 , and 28 in a generalized form (refer to equation 7):

$$
\begin{aligned}
& F_{1}(j \delta)=T_{1} X_{j, o}-T_{n} Y_{j, o} \\
& F_{n}(j \delta)=T_{1} Y_{j, o}-T_{n} Z_{j, o}
\end{aligned}
$$

where the temperature amplitudes of the triangular pulses in equations 22 , initiated at time equal zero, are $\mathrm{T}_{1}$ and $\mathrm{T}_{\mathrm{n}}$ at the exposed surfaces. Typical response to a unit triangular pulse at an exposed surface is shown in figure 2 .

For a continuous set of triangular temperature pulses of aribitrary amplitudes and placed at a time interval $t=\delta$ apart, the heat flux at a time $t=\tau$ becomes $a$ linear combination of present and past temperature pulses and the respective solutions from (26), (27) and (28). Using this principle of superposition, the heat flux relations become:

$$
\begin{aligned}
& F_{1, \tau}=\sum_{j=1}^{L} X_{j, o} T_{1, \tau-j+1}-Y_{j, o} T_{n, \tau-j+1} \\
& F_{n, \tau}=\sum_{j=1}^{L} Y_{j, o} T_{1, \tau-j+1}-Z_{j, \circ} T_{n, \tau-j+1}
\end{aligned}
$$


This can best be illustrated by referring to figure 3, which shows a set of overlapping isosceles triangles connected at their peaks by straight lines. The rationale is to imagine that the effect of each separate temperature pulse in past time will have some contribution to the heat flux at the present time.

The nature of the resultant temperature distribution is assumed linear between each pulse. This seems intuitively obvious when one observes that the area of overlap is identically equal to the open area under the straight line drawn between two adjacent pulses. A verification of response factors was performed in reference 2 where $f(f)$ and $g(t)$ in (17) are defined by trigonometric series and the results were compared to confirm the linear variation between temperature pulses. 


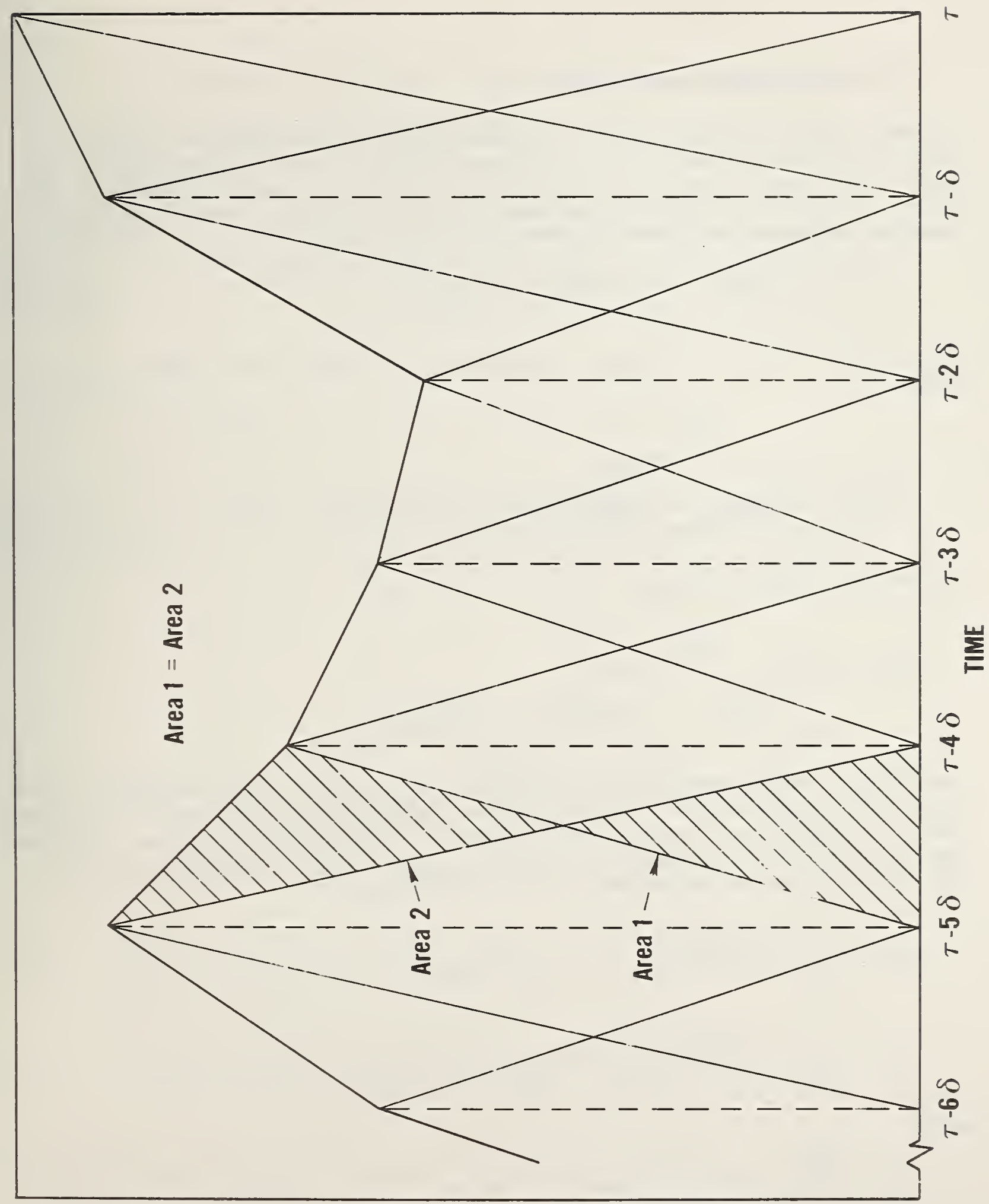

\section{$7 \forall I \perp N \exists 10 d \exists y \cap \perp \forall y \exists d W \exists \perp$}

Figure 3. Set of overlapping triangular temperature pulses. 


\section{CONDUCTION TRANSFER FUNCTIONS}

For some types of construction, the number of terms in equations 31 and 32 needed to obtain accurate results is inordinately large for computational purposes. For this reason, it is necessary to reduce the number of terms. One way to do this is to define a response factor or a zeroth order conduction transfer function for $j$ greater than three as follows:

$$
W_{j, 0}=P_{1} e^{-j \beta_{i}^{2} \delta}+P_{2} e^{-j \beta_{2}^{2} \delta}+P_{3} e^{-j \beta_{3}^{2} \delta}+\ldots
$$

from (28) such that $\beta_{i}<\beta_{i+1}$. To eliminate the first term, perform the operation

$$
\begin{aligned}
W_{j, 1} & =W_{j, 0}-e^{-\beta^{2} \delta} W_{j-1,0} \\
& =P_{2} e^{-j \beta_{2}^{2} \delta}\left[1-e^{\left(B_{2}^{2}-\beta_{1}^{2}\right)_{\delta}}\right]+\ldots
\end{aligned}
$$

Continuing one step further

$$
\begin{aligned}
W_{j, 2} & =W_{j, 1}-e^{-B_{2}^{2} \delta} W_{j-1,1} \\
& =P_{3} e^{-j \beta_{3}^{2}}\left[1-e^{\left(B_{3}-B_{2}^{2}\right) \delta}\right]\left[1-e^{\left(B_{3}^{2}-B_{1}^{2}\right) \delta}\right]+\ldots
\end{aligned}
$$

This process can be continued to give $W_{j}, 3, W_{j}, 4$, etc. From the above, it can be seen that the modified response factors become smaller and smaller in magnitude to a point where they can be ignored for computational purposes. Performing the operation $F_{1, t}-R_{1} F_{1, t-1},\left(F_{1, t}-R_{1} F_{1, t-1}\right)-R_{2}\left(F_{1, t-1}-R_{1}, F_{1, t-2}\right)$ etc., (31) and (32) can be transformed to the following form

$$
\begin{aligned}
& F_{1, t}=\sum_{m=1}^{k}(-1)^{m+1} S_{m} F_{1, t-m}+\sum_{j=1}\left(X_{j, k} T_{i, t-j+1}-Y_{j, k} T_{0, t-j+1}\right) \\
& F_{n, t}=\sum_{m=1}^{k}(-1)^{m+1} S_{m} F_{n, t-m}+\sum_{j=1}\left(Y_{j, k} T_{i, t-j+1}-Z_{j, k} T_{0, t-j+1}\right)
\end{aligned}
$$

where

$$
R_{m}=e^{-\beta_{m}^{2} \delta}
$$

and

$$
\begin{aligned}
& s_{1}=R_{1}+R_{2}+R_{3}+R_{4}+R_{5} \\
& s_{2}=R_{1}\left(R_{2}+R_{3}+R_{4}+R_{5}\right)+R_{2}\left(R_{3}+R_{4}+R_{5}\right)+R_{3}\left(R_{4}+R_{5}\right)+R_{4} R_{5}
\end{aligned}
$$




$$
\begin{aligned}
& S_{3}=R_{1} R_{2}\left(R_{3}+R_{4}+R_{5}\right)+R_{1} R_{3}\left(R_{4}+R_{5}\right)+R_{4} R_{5}\left(R_{1}+R_{2}+R_{3}\right)+R_{2} R_{3}\left(R_{4}+R_{5}\right) \\
& S_{4}=R_{1} R_{2}\left(R_{3} R_{4}+R_{3} R_{5}+R_{4} R_{5}\right)+R_{3} R_{4} R_{5}\left(R_{1}+R_{2}\right) \\
& S_{5}=R_{1} R_{2} R_{3} R_{4} R_{5}
\end{aligned}
$$

In equation 33, for the case when the temperature $T_{i}$ is constant and $T_{0}$ is zero for all times, the heat fluxes are equal and constant due to the steady-state condition, then the conductance of the construction is solved for by the relationship

$$
C=\frac{F_{i}}{T_{i}}=\frac{\sum_{j=1} X_{j, k}}{1+\sum_{m=1}^{k}(-1)^{m_{S}} S_{m}}
$$

Comparison of the thermal conductance of a construction with values computed from (35) is needed as a check on the accuracy of the computed conduction transfer functions. 


\section{INITIALIZATION OF SURFACE TEMPERATURES AND HEAT FLUXES}

Conduction transfer functions are analytically derived with an initial time condition of zero temperature potential throughout the solid(s). This is not a realistic initial condition for the use of conduction transfer functions to an existing building that has been exposed to outdoor weather cycles before the need to determine heat flow through the building construction. For this reason it becomes necessary for the building construction to be exposed to a number of outdoor weather cycles such that satisfactory initial conditions of temperature and heat flux history exist at the inside and outside surfaces before subjecting the building construction to the actual outdoor weather variation.

Presently the initialization is performed on an arbitrary basis and is seriously in need of quantification, especially in regard to very thick or heavy-weight constructions. For lightweight constructions such as wood frame walls, only two or three diurnal weather cycles are necessary for initialization. But with an increase in thickness or weight per unit surface area, the necessary number of diurnal cycles can be considerably increased.

There are many ways by which initialization may be accomplished, but one way to substantiate that initialization has been completed is to use repeated identical diurnal weather cycles. Here, for a diurnal cycle, the average heat flux at the inside and outside surfaces will be approximately equal after exposure to a sufficient number of cycles.

An example of initialization is given in table 2, which gives the ratio of the average heat flux at both the outside and inside surface for a diurnal cycle to the average cyclic heat flux which would occur under steady periodic conditions. The tabular values were computed for $1 / 2,1,2$, and 3 feet of heavyweight concrete ( $120 \mathrm{lbs} / \mathrm{ft}^{3}$ ) and indicate that as the thickness increases, the number of cycles necessary to achieve initialization also increases.

Initialization is accomplished in subroutine PI, which in turn picks up the outdoor and indoor temperature variations and the inside and outside surface coefficient of heat transfer for a 24-hour period from a calling program. This subroutine calls subroutine $P Q$ to determine $W_{O}, t$ and $W_{i}, t(3)$ and $(4)$, to be used in the simultaneous solution involving $(1),(5),(2)$ and (6). Solution for the present surface temperature is found in subroutine $P R$ as well as the solution for $Q_{o, t} Q_{i, t}(1)$ and (2). This subroutine also updates the temperatures and heat fluxes. For every 24-hour period, the subroutine PI sums the heat flux and temperatures at the outside and inside surfaces for the separate building constructions, and prints out the values.

The subroutine PI was developed to illustrate initialization and is not necessarily recommended for use in working computer programs. This is because there are so many applications for conduction transfer functions as to types of heat balance involving the surface temperature that it would be impossible to devise a subroutine to be all-encompassing. The subroutines $P I, P R$ and $P Q$ are mainly to give as an example the use of conduction transfer functions in conduction heat transfer problems. 
Table 2. Number of Cycles Needed to Obtain Initialization

Value of Ratio = average heat flux for cycle

average heat flux steady periodic cycle

at outside and inside surface of heavyweight concrete

of various thicknesses $\left(\mathrm{K}=1 \mathrm{Btu} \mathrm{h}^{-1} \mathrm{ft}^{-2} \mathrm{~F}^{-1}, \rho=1201 \mathrm{bft}^{-3}\right.$,

$\mathrm{C}=0.2 \mathrm{Btu} 1 \mathrm{~b}^{-1} \mathrm{~F}^{-1}$ )

Cycle

No.

Thickness of concrete, ft.

\begin{tabular}{|c|c|c|c|c|c|c|c|c|}
\hline & \multicolumn{2}{|c|}{$1 / 2$} & \multicolumn{2}{|c|}{1} & \multicolumn{2}{|c|}{2} & \multicolumn{2}{|c|}{3} \\
\hline & outside & inside & & & & & & \\
\hline 1 & .769 & .368 & 1.062 & .218 & 1.625 & .049 & 2.179 & .008 \\
\hline 2 & 1.095 & .950 & 1.297 & .820 & 1.902 & .445 & 2.554 & .167 \\
\hline 3 & 1.000 & 1.000 & 1.001 & .993 & 1.218 & .820 & 1.602 & .491 \\
\hline 4 & & & 1.000 & 1.000 & 1.064 & .947 & 1.305 & .730 \\
\hline 5 & & & & & 1.019 & .985 & 1.159 & .858 \\
\hline 6 & & & & & 1.005 & .996 & 1.083 & .925 \\
\hline 7 & & & & & 1.002 & .999 & 1.044 & .960 \\
\hline 8 & & & & & 1.000 & 1.000 & 1.024 & .978 \\
\hline 9 & & & & & & & 1.014 & .987 \\
\hline 10 & & & & & & & 1.008 & .992 \\
\hline 11 & & & & & & & 1.005 & .995 \\
\hline 12 & & & & & & & 1.004 & .996 \\
\hline 13 & & & & & & & 1.004 & .997 \\
\hline 14 & & & & & & & 1.003 & .997 \\
\hline 15 & & & & & & & 1.003 & .997 \\
\hline 16 & & & & & & & & \\
\hline
\end{tabular}




\section{CONCLUSIONS}

Conduction transfer functions are closed-form analytical solutions for one-dimensional conduction heat flow in single or multi-layer building constructions based on a knowledge of temperature and heat flux history occuring at constant time intervals. Values of heat flux obtained by this method are based on the assumption that the temperature varied linearly over the time interval (ref. 2). The use of the principle of superposition or use of a set of overlapping triangular temperature pulses is possible for the solutions to linear, homogeneous, partial differential equations (ref. 4), when the solution becomes a linear combination of the separate solutions.

Conduction transfer functions of $k t h$-order are generated from the zeroth order by the following recursion formula:

$$
\mathrm{W}_{\mathrm{n}, \mathrm{k}}=\mathrm{W}_{\mathrm{n}, \mathrm{k}-1}-\mathrm{e}^{-\beta_{\mathrm{k}}^{2} \delta} \mathrm{W}_{\mathrm{n}-1, \mathrm{k}-1}
$$

where $\beta_{k}$ is the kth roof of (17), $n$ are integers greater than one, and values for $k-1=0$ are defined by (26), (27), and (28). The heat fluxes at the inside and outside surfaces are then given by (33) and (34).

The output of subroutine PC provides conduction transfer functions and coefficients of past heat flux history by which the heat flux (eqs. 33 and 34 ) may be evaluated. The routine needs two additional subroutines, $A B C$ and ROOTS.

Particular features of the program subroutine are:

1. When an enclosed air space occurs within a building construction, the thermal diffusivity is assumed to be $0.75 \mathrm{ft}^{2} / \mathrm{h}$. If the thickness is not defined for the air space, it is assigned a value 0.08333 foot ( 1 inch). The thermal conductivity is then defined as the thickness divided by the thermal resistance.

2. The program allows for the combination of two building constructions that would act as parallel heat flow paths in a wall, roof or floor. An example would be wood-frame walls with the cavity and wood studs as two separate constructions through which heat must pass. The resulting conduction transfer functions are linear combinations of the ratio of area to the total area and the conduction transfer functions for each construction.

3. The present program is intended for the use of 1-, 2-, or 3-hour time intervals. For thick building constructions (usually thicknesses greater than 3 feet), a 1-hour time interval is not a sufficiently large value for allowing the effects of temperature history on one surface to be transmitted to the heat flux on the other surface. By allowing the 2- or 3-hour time interval, the effects are more noticeable, as evidenced in values for $\mathrm{Y}_{\mathrm{n}, \mathrm{o}}$, which transmits the temperature potential on one surface to the other surface. 
6. DESCRIPTION OF SUBROUTINES FOR DETERMINING CONDUCTION TRANSFER FUNCTIONS

\subsection{SUBROUTINE PC}

\section{SUBROUTINE PC(IR)}

\section{Description}

This subroutine calculates the conduction transfer functions of order $k, \mathrm{x}_{\mathrm{n}, \mathrm{k}}$, $\mathrm{Y}_{\mathrm{n}, \mathrm{k}}, \mathrm{Z}_{\mathrm{n}, \mathrm{k}}$ that are necessary to determine the dynamic conduction heat transfer through building constructions.

The approach taken by subroutine PC is presented in reference 2 for determining response factors and in reference 1 for determining conduction transfer functions. Equations 26, 27, and 28 are closed-form solutions for heat flow at the two exposed surfaces of single and multi-layer bullding constructions. Determination of the roots of equation 17 for multi-layer slabs presents the most difficulty due to the unpredictable nature of the equation.

Subroutine Calling This Routine

MAIN PROGRAM

Subroutines Called by This Routine

SUBROUTINE ABC

SUBROUTINE ROOTS

Common Blocks

$$
\text { /CBA/ }
$$

/CZ/
Variables Placed in Common Blocks

$$
X X, Y Y, Z Z, R, N T R, U
$$

\section{Declarations}

DIMENSION $\mathrm{S}(64), \mathrm{B}(7), \mathrm{C}(6), \mathrm{E}(6), \mathrm{L}(8), \mathrm{K}(8), \mathrm{SP}(8), \mathrm{RE}(8)$, $1 \mathrm{RM}(8,60), \mathrm{D}(8), \mathrm{AL}(7), \mathrm{Y}(50), \mathrm{X}(50), \mathrm{W}(50), \mathrm{T}(50), \mathrm{Z}(5), \mathrm{A}(20,6), \mathrm{P}(20,6)$, $2 \mathrm{~V}(20,6)$

DATA ST/ $1 \mathrm{H} * /$

REAL $K, L$ 
Input

Source of Data Name

Card Image

JA, IN, JB

Card Images

Card Image
$L, K, D, S P$,

$\mathrm{RE}, \mathrm{RM}$
Description

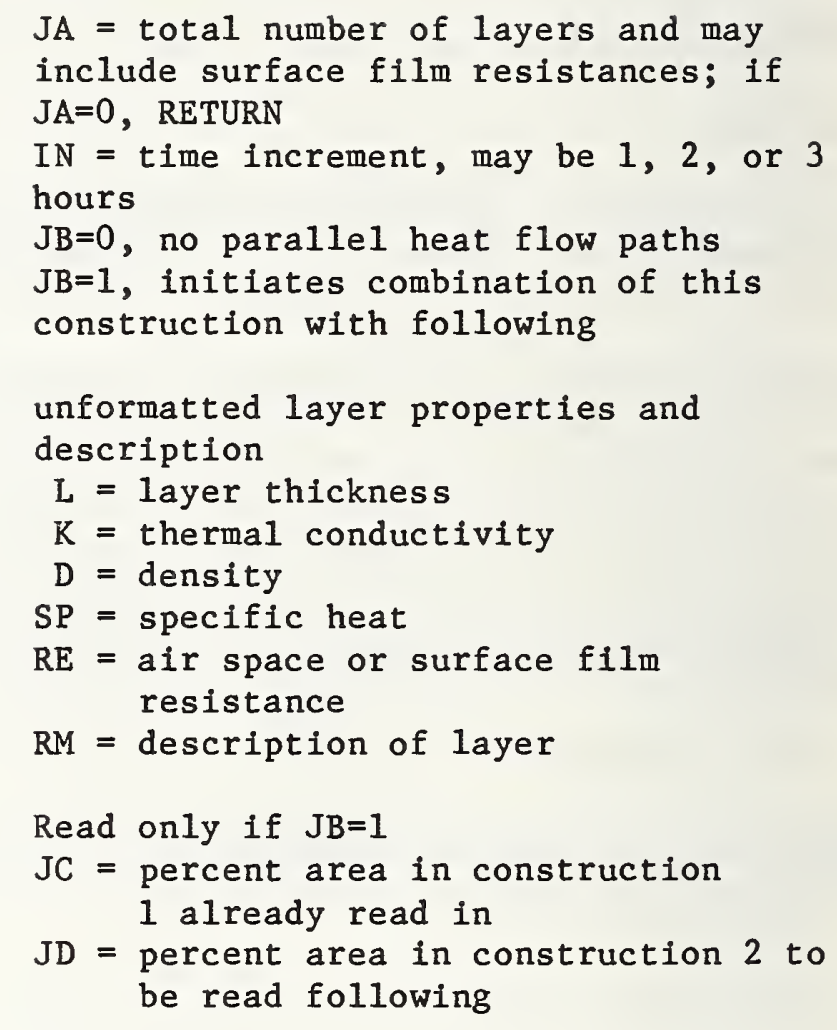

JA, IN, JC, JD

Output for Computation (labelled common)

Name

\begin{tabular}{|c|c|}
\hline$X X(I R, L)$ & $\begin{array}{c}x_{n,} k^{t h} \text { order conduction transfer functions for construction } \\
\quad I R=1,2, \ldots, n=1,2,3, \ldots, L\end{array}$ \\
\hline$Y Y(I R, L)$ & $\mathrm{Y}_{\mathrm{n}, \mathrm{k}}$ eq. 33,34 \\
\hline$Z Z(I R, L)$ & $\mathrm{z}_{\mathrm{n}, \mathrm{k}}$ eq. 34 \\
\hline$R(I R, K)$ & $\mathrm{J}_{\mathrm{m}}$ heat flux coeffficients, eq. $33,34, \mathrm{~m}=1,2, \ldots, \mathrm{k}$ \\
\hline$U(I R)$ & $\mathrm{U}$ building construction conductance \\
\hline NTR & $\begin{array}{l}\operatorname{NTR}(\operatorname{IR}, 1)=\mathrm{L}, \text { number of conduction transfer functions } \\
\operatorname{NTR}(\operatorname{IR}, 2)=\mathrm{K} \text {, number of heat flux coefficients } \\
\operatorname{NTR}(\operatorname{IR}, 3)=\mathrm{J} \text {, time interval, } \delta\end{array}$ \\
\hline
\end{tabular}


1. Set IR=0, a counter for describing the number for a building construction.

2. For each building construction, the total number of layers, time interval, and parallel heat flow indicators are read in followed by a separate card image for each layer which includes on each card the thickness, thermal conductivity, density, specific heat, thermal resistance, and the layer description. If the first and last layer densities are each less than .001 , the thermal resistance(s) are defined for the inside and outside surface $\mathrm{film}$ resistances, and the number of layers is reduced by the number of surface film resistances. If the resulting value for the number of layers is greater than seven, the subroutine is exited by a return to the calling routine.

3. The thermal diffusivity for each layer is calculated from the ratio of the thermal conductivity to the product of the density and specific heat. For an air space, the thermal diffustivity is set equal to 0.75 . If no air space thickness is defined, the thickness is set equal to 0.08333 and the thermal conductivity is set equal to the thickness divided by the air space thermal resistance.

For each layer, the thickness divided by the square root of the thermal diffusivity is defined (loop 20). Values for $k_{m}$ (from eq. 14) are defined (loop 21). Values for $\mathrm{N}_{\mathrm{m}}$ and $\mathrm{E}_{\mathrm{m}}$ are defined (see definitions following eq. 14 and table 1 by statements 1 to 7 , according to the value $J$ for the number of layers).

4. The summation terms for evaluation of $A_{1}, A_{2}, B_{1}, B_{2}, C_{1}$, and $C_{2}$ are determined in subroutine $A B C(I=1)$ for evaluation of equations 23,24 , and 25, $t=\delta$. Values of $A_{1}$ and $A_{2}$ are used to give an initial estimate to the first root of (17). Subroutine ROOTS determines the roots of (17) and the individual terms in the series of (26) for $X_{1}, 0, Y_{1,0}$, and $Z_{1}, 0$ which are defined in loop 50, as well as $X_{2}, 0, Y_{2,0}$, and $Z_{2,0}$ (eq. 27). Values for $X_{j, 0}, Y_{j, 0}$, and $Z_{j}, 0(j-3,4, \ldots, 20)$ are defined in loop 56 (eq. 28). For ${ }_{1}{ }^{\prime}$ less than $0.12^{\prime}$ it has been shown that $Y_{1,0}$ and $Y_{2}, 0$ are negligibly small and that the values are sometimes the result of loss of significance in their determination and are therefore set equal to zero.

5. If the initial estimate for $\beta_{1}$ (eq. 21) is less than 0.15 , the time interval is set equal to 2 . If the estimate is less than 0.10 , the time interval is set equal to 3 .

6. A criterion for the order of the conduction transfer functions is:

$$
\left[\left|\mathrm{x}_{20, \mathrm{k}}\right|+\left|\mathrm{Y}_{20, \mathrm{k}}\right|+\left|\mathrm{z}_{20, \mathrm{k}}\right|\right] \leq 4 \times 10^{-6} \text {. }
$$

if the relationship is not satisfied, the next greater order is computed ( $\left.B_{s k} \leq 5\right)$ from the recursion relationship. 


$$
\mathrm{W}_{\mathrm{n}, \mathrm{k}}=\mathrm{W}_{\mathrm{n}, \mathrm{k}-1}-\mathrm{e}_{\mathrm{k}}^{-\mathrm{\beta}^{2} \delta} \mathrm{W}_{\mathrm{n}-1, \mathrm{k}-1}
$$

Once the criterion is satisfied, the coefficients of past heat flux history are computed and the computed thermal conductanes (35) are compared to conductance computed from the input properties of the building construction. If the denomination of (35) is less than $15^{4}$, either this time interval is measured (but not greater than three hours) or the building construction thickness is reduced by a factor of 0.95 and the conduction transfer functions are recomputed.

7. The number of conduction transfer functions $(1 \leq L \leq 20)$, to be used in heat flux calculations is determined from the criterion:

$$
\left[\left|\mathrm{X}_{\mathrm{L}, \mathrm{k}}\right|+\left|\mathrm{Y}_{\mathrm{L}, \mathrm{k}}\right|+\left|\mathrm{z}_{\mathrm{L}, \mathrm{k}}\right|\right]<.7 \times 10^{-7}
$$

8. When the parallel heat flow indicator, JB equals 1 , the zeroth order conduction transfer functions are computed for both building constructions. The ratio of the areas of the constructions to the total area, JC and JD, are input, before the second building construction. A linear combination of the respective areas and the conduction transfer functions gives a resultant conduction transfer function for the parallel heat flow path. Computation then continues at step 6 above.

\subsection{SUBROUTINE ABC}

SUBROUTINE $A B C(X, Z, J, I)$

\section{Description}

This subroutine computes summation elements needed for $(I=0)$ determining roots of the characteristic equation 17, and values for (18). It also computes summation elements needed for ( $I=1$ ) determining $A_{1}, A_{2}, B_{1}, B_{2}, C_{1}$, and $C_{2}$ for substitution in equations $21,23,24$, and 25 .

\section{Subroutine Calling This Subroutine}

PC

ROOTS

\section{Subroutine Called by This Routine}

None

\section{Common Blocks}

/CBA/

$$
\begin{aligned}
& \text { Variables Obtained } \\
& \text { from Common Blocks }
\end{aligned}
$$

$S(64), C(6)$
Variables Placed in Common Blocks

None 
Declarations

DIMENSION $Z(1), T(64), V(64,4)$

Input

Source of

Data

Name

Description

/CBA/

$S(64)$

$\mathrm{N}_{\mathrm{m}}, \mathrm{m}=1,2, \ldots, 32$

$E_{m}, M+32=33,34, \ldots, 64$

equations 13 and 14

/CBA/

$c(6)$

$k_{i}, i=1,2, \ldots, 6$

equations 13 and 14

ROOTS

$\mathrm{X}$

Values of $\beta$ for computing summation elements of equations 17 and 18

PC, ROOTS

$\mathrm{J}$

Number of layers in building construction

PC , ROOTS

$I=0$, gate for determining summation elements for equations 17 and 18 .

$I=1$, gate for determining summation elements for equations $21,23,24$ and 25 .

Output

Name

$Z(I=0)$

$Z(I=1)$

\section{Description}

$\mathrm{Z}(1)=\Sigma \mathrm{J}_{\mathrm{m}} \sin \mathrm{N}_{\mathrm{m}} \beta$

$\mathrm{Z}(2)=\sum \mathrm{J}_{\mathrm{m}} \cos \mathrm{N}_{\mathrm{m}} \beta$

$\mathrm{Z}(3)=\sum \mathrm{J}_{\mathrm{m}} \mathrm{N}_{\mathrm{m}} \cos \mathrm{N}_{\mathrm{m}} \beta$

$\mathrm{Z}(4)=\Sigma \mathrm{J}_{\mathrm{m}} \mathrm{N}_{\mathrm{m}} \sin \mathrm{N}_{\mathrm{m}} \beta$

$Z(5)=\Sigma L_{m} \sin E_{m} \beta$

$\mathrm{Z}(6)=\Sigma \mathrm{L}_{\mathrm{m}} \cos E_{\mathrm{m}} \beta$

$Z(7)=\Sigma L_{m} E_{m} \cos E_{m} \beta$

$\mathrm{Z}(8)=\sum \mathrm{L}_{\mathrm{m}} \mathrm{E}_{\mathrm{m}}$ sin $\mathrm{E}_{\mathrm{m}} \beta$

$\mathrm{Z}(1)=\Sigma \mathrm{J}_{\mathrm{m}}$

$\mathrm{Z}(2)=\sum \mathrm{J}_{\mathrm{m}} \mathrm{N}_{\mathrm{m}_{2}}$

$\mathrm{Z}(3)=\sum \mathrm{J}_{\mathrm{m}} \mathrm{N}_{\mathrm{m}}$

$\mathrm{Z}(4)=\Sigma \mathrm{J}_{\mathrm{m}}^{\mathrm{N}} \mathrm{N}^{3}$

$\mathrm{Z}(5)=\Sigma \mathrm{L}_{\mathrm{m}}$

$\mathrm{Z}(6)=\Sigma \mathrm{L}_{\mathrm{m}} \mathrm{E}_{\mathrm{m}_{2}}$

$\mathrm{Z}(7)=\Sigma \mathrm{L}_{\mathrm{m}} \mathrm{E}_{\mathrm{m} 3}$

$\mathrm{Z}(8)=\sum \mathrm{L}_{\mathrm{m}} \mathrm{E}_{\mathrm{m}}$ 


\section{Calculation Procedure}

1. Set $K=1$, if $I=1$, go to 20 ; if $I=0$, refer to calculation procedure 3 .

for $\mathrm{K}=1$

for $K=2$

for $K=3$

for $K=4$

$$
\begin{aligned}
& T(N)=1 \\
& T(N)=S(N) \\
& T(N)=S(N)^{2} \\
& T(N)=S(N)^{3}
\end{aligned}
$$$$
N=1 \text { to } 64
$$

2. For each value of $\mathrm{K}$ with the assigned values for $\mathrm{T}(\mathrm{N})$, from statement 40 , $\mathrm{Y}=\mathrm{W}=0$, an assigned $\mathrm{GO}$ TO statement based on the number of layers sends control to the appropriate location to give the summations.

$Y=\sum J_{m} T(N), W=\sum L_{n} T(N), J_{n}$ and $L_{n}$ 's are defined in table 1 . When $K$ is greater than 4 , a return is made to the calling routine.

3. for $\mathrm{K}=1$

$\mathrm{K}=2$

$\mathrm{K}=3$

$\mathrm{K}=4$

$$
\begin{aligned}
& T(N)=\sin \beta * S(N) \\
& T(N)=\cos \beta * S(N) \\
& T(N)=S(N) \cos \beta * S(N) \\
& T(N)=S(N) \sin \beta * S(N)
\end{aligned}
$$

Use calculation procedure 2 above.

\subsection{SUBROUTINE ROOTS}

SUBROUTINE ROOTS ( $A B, A C, A D, V 1, V 2, D E L, B, Z, P, R, J, M$ )

\section{Description}

This subroutine calculates the positive roots of equation 17 . It also computes equation 18 and common portions of the summation terms of the response factors (see equations 26,27 , and 28 ). It is essential that all the positive roots of (18) be computed up to a value of about 5.5 . If any roots are missed erroneous values for the response factors will result. Any algorithm for finding the roots of (18) must be used with caution because the nature of some building constructions will give unpredictable behavior to the equation. Because equation 18 is the derivative of equation 17, the Newton-Raphson method for finding roots is used when in the vicinity of the root.

\section{Subroutine Calling This Routine}

PC

\section{Subroutine Called by This Routine}

$\mathrm{ABC}$

\section{Common Blocks}

None 
Declarations

DIMENSIONS $B(1), Z(1), P(1), R(1), Y(8)$

\section{Input}

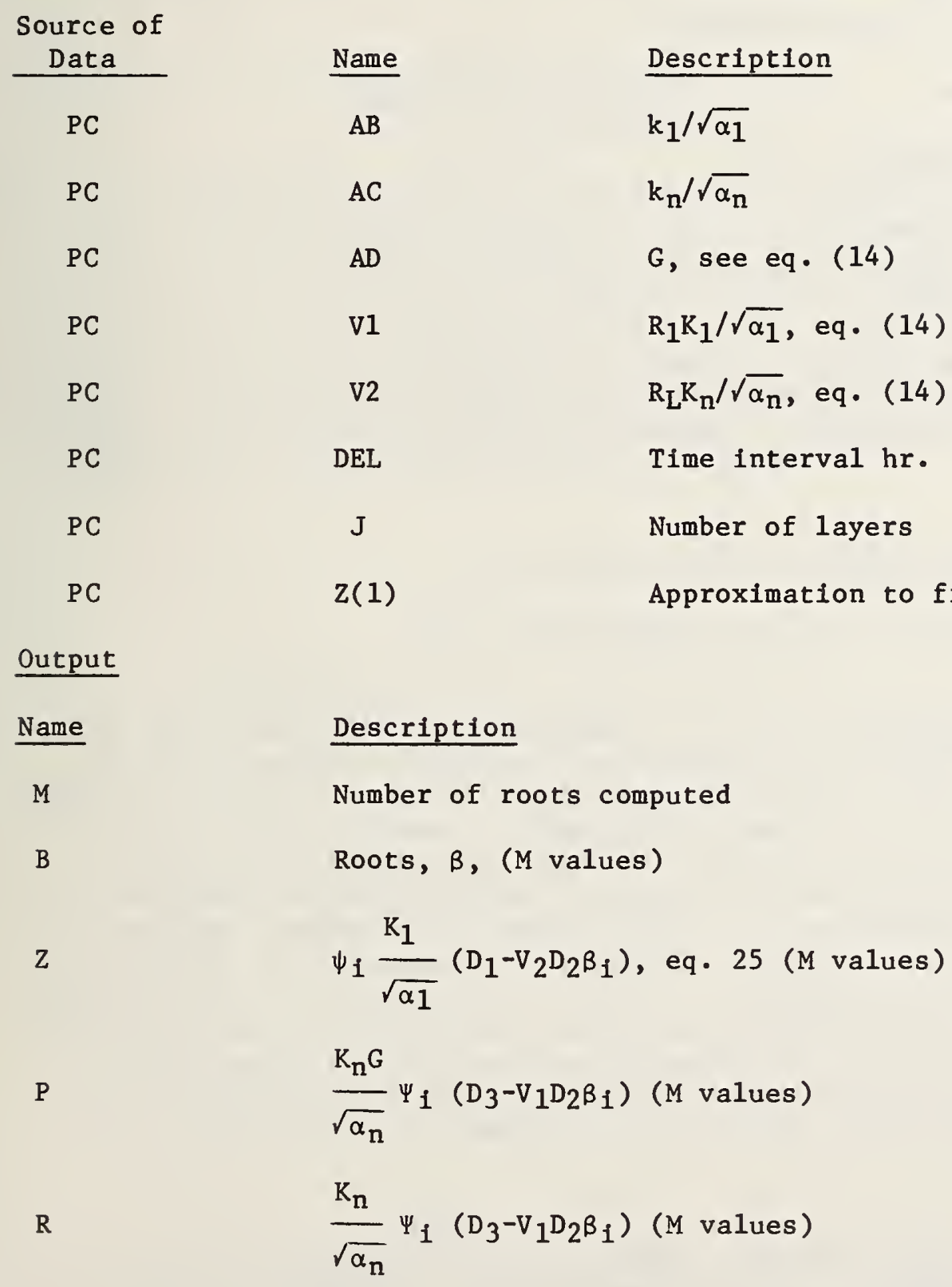




\section{Calculation Procedure}

1. Initialize

$I=0$, gate for use in subroutine $A B C$

$M=1$, count on number of roots computed

$\mathrm{K}=0$, iteration counter

$\mathrm{U}=0.1$, tentative increment

$V=V_{1} * V_{2}$, see $W(\beta)$, eq. 17

$G=V_{2}-V_{1}$, see $W(\beta)$, eq. 17

$\mathrm{H}=\mathrm{V}_{2}-\mathrm{V}_{1}$, see $\mathrm{W}(\beta)$, eq. 17

$A=B=.005$

$D=W(.005)$

$X=Z(1)$, initial approximation to first root, eq. 21

$\mathrm{E}=.15 \mathrm{X}$, initial increment used for finding first root.

2. Root finding loop begins with statement 10. Call subroutine $A B C$ to calculate $A=W(\beta)$ and $Q=W^{\prime}(\beta)$. If $A$ is less than $.2 \times 10^{-6}$, the value $X=\beta$ is considered to be the root and exits from the loop to statement 50. If $\mathrm{A} / \mathrm{Q}$ is less than $5 \times 10^{-4}$, computation goes to statement 40 . If the iteration counter $\mathrm{K}$ is greater than 2, computation goes to statement 40 . If the product $A^{*} D$ is positive, go to statement 30 where the present increment is added to $X$. If the product $A * D$ is negative, incrementing has gone past the value for root go to statement 20 , which subtracts the present increment; reduce the increment by one-half. If $M=1$, go to statement 10; otherwise the iteration counter $\mathrm{K}$ is increased by 1 and go to statement 10 . In statement 30 , the value of $X$ is increased by the present value for the increment $E$; in statement 40 , the value of $X$ is changed using the Newton-Raphson Method, $X=X-A / Q\left[\beta_{n+1}=\beta_{n}-W\left(\beta_{n}\right) / W^{\prime}(B)\right]$, iteration counter $K$ is increased by one. If $K$ is greater than 9, exit from loop to statement 50; otherwise go to statement 10 .

3. Statement 50, store $\operatorname{root} \beta(M)=X=\beta_{m}$, compute $\Psi_{m}=2 e^{-\beta_{m}^{2} \delta} / \beta_{m}^{2} \delta W^{\prime}(B), Z(M)$ $P(M)$, and $R(M)$ for output. If $\beta_{m}$ is greater than 5.5, RETURN to subroutine $P C$, if $M$ is greater than 50, RETURN to subroutine PC. Set iteration count to zero.

4. The initial increment for the determination of each root is based on the magnitude of the first root, or 


$$
\begin{aligned}
& U=0.1 \\
& U=.005 \\
& U=.002 \\
& U=.001
\end{aligned}
$$

5. Initialize

$$
\begin{aligned}
& \mathrm{C}=\mathrm{X}=\beta_{\mathrm{m}} \\
& \mathrm{E}=\mathrm{U} \\
& \mathrm{M}=\mathrm{M}+1 \\
& \mathrm{~N}=1
\end{aligned}
$$

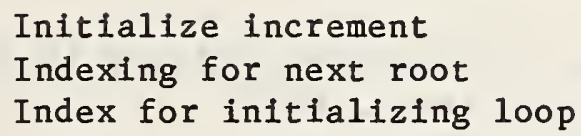

6. Initializing root finding loop starts with statement 70 . Increment $C$ by the value of $E$, call subroutine $A B C$ in order to calculate $A=W(B), Q=W^{\prime}(B)$. If $N=1$, set $D=A$ and $S=Q$. At statement 80 , increase index $N$ by 1 , increase increment $E$ by the initial increment $U$ and go to statement 70 . If $N$ is greater than 1 , go to statement 90 ; if $A^{*} D$ is less than zero, go to statement 100 ; if $A / Q$ or $W(B) / W^{\prime}(B)$ is greater than zero, go to statement 80 above. If $A / Q$ is less than zero, the increment $E$ is set equal to $2 U, X=C+E$ and go to statement 10 (see item 2 above). Statement 100 , the present $\mathrm{E}$ is divided by 2 , then $\mathrm{X}=\mathrm{C}-\mathrm{E}$ and go to statement 10 . 


\section{REFERENCES}

1. B. Peavy, "A Note on Response Factors and Conduction Transfer Functions," ASHRAE Transactions, Volume 84, Part 1, 1978.

2. B. Peavy, "Determination and Verification of Thermal Response Factors for Thermal Conduction Applications," NBSIR 77-1405, National Bureau of Standards, April 1978.

3. H. S. Carslaw and J. C. Jaeger, "Operational Methods in Applied Mathematics," Second Edition, Oxford University Press, 1948.

4. M. Lokmanhekim, "Convolution Principle as Applied to the Heat Transfer Problems of Buildings and Fundamentals of Its Efficient Use," LBL-6866, Lawrence Berkeley Laboratory, University of California, August 1977. 
\% 它完崩 So․․ 츤온였 岗. x $>$ 絮 造证

年

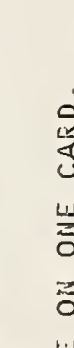

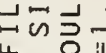

똔꼰

यั잉

这。

气

$\frac{2}{4}$

w

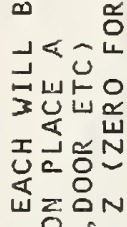
w次 는응 结运

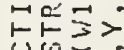
$3 x$ 언하 的的 比嵒 u< 4 L 这z 남흔 남언 눈 $\infty$.

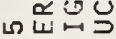
으닐을 안로엉 今录式崖 $15<$ 岂比范岁 这㓉

$5 \dot{2}::$ เด: :

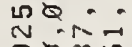
करल $\Psi Q Q Q Q$ 至

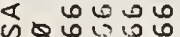
Q60.0.0

产

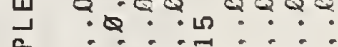

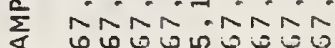

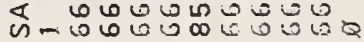

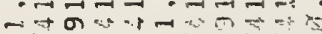

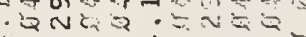
要

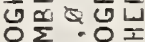

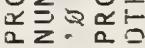

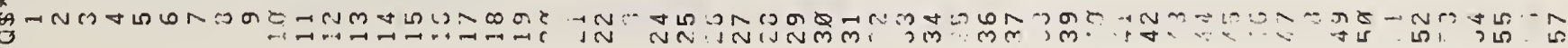

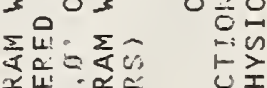

놇

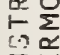



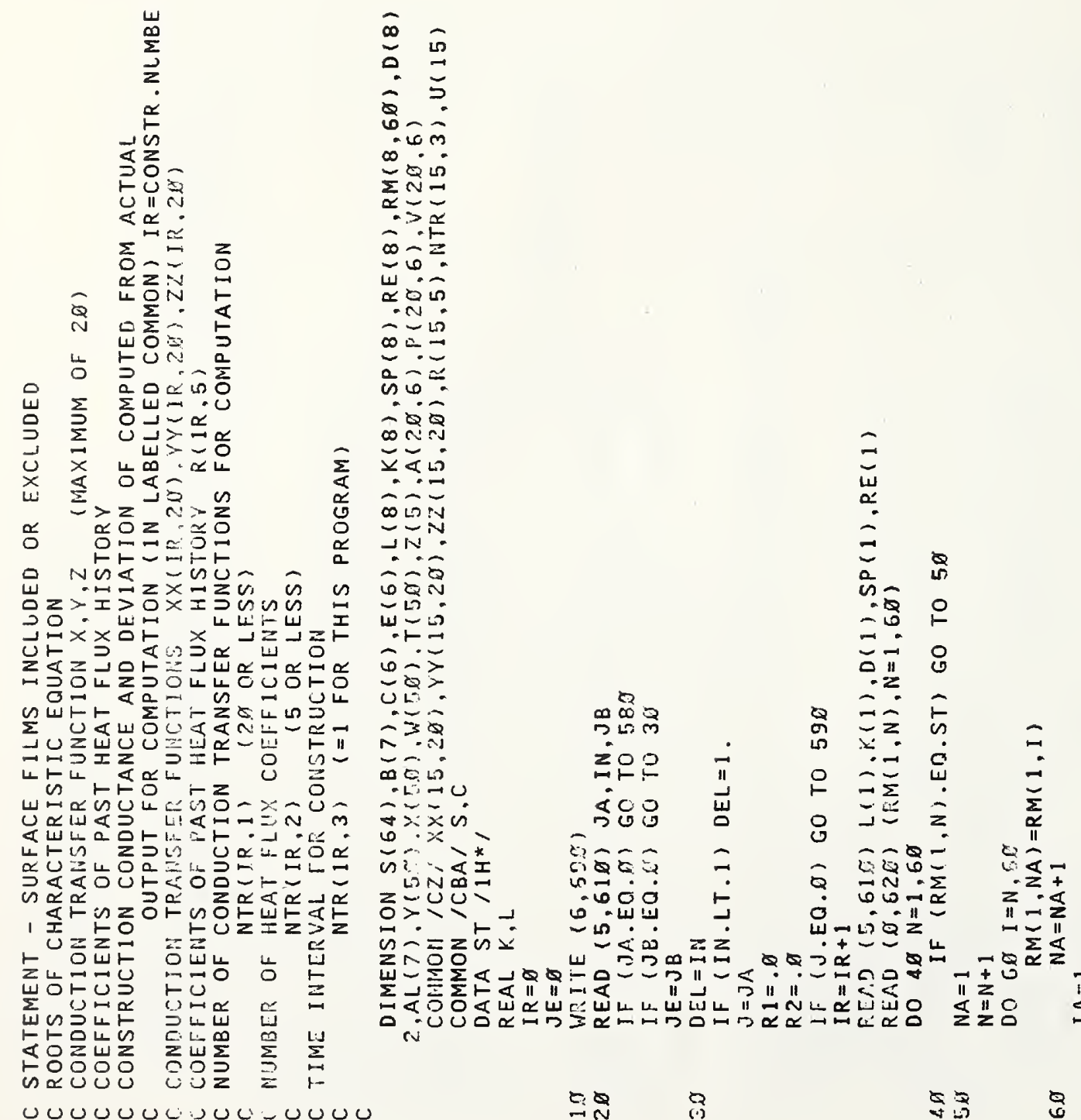

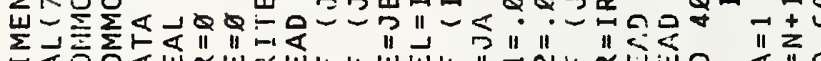

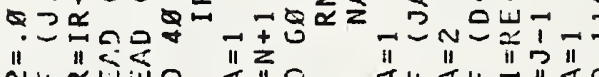

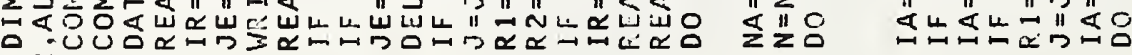

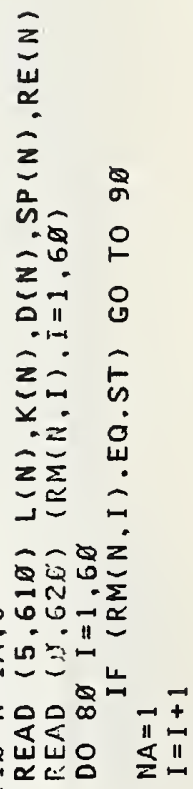

요
tid

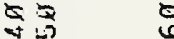
$\stackrel{Q}{\wedge} \stackrel{\infty}{Q}$

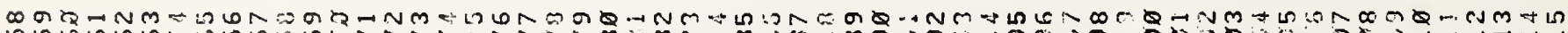
几ा 


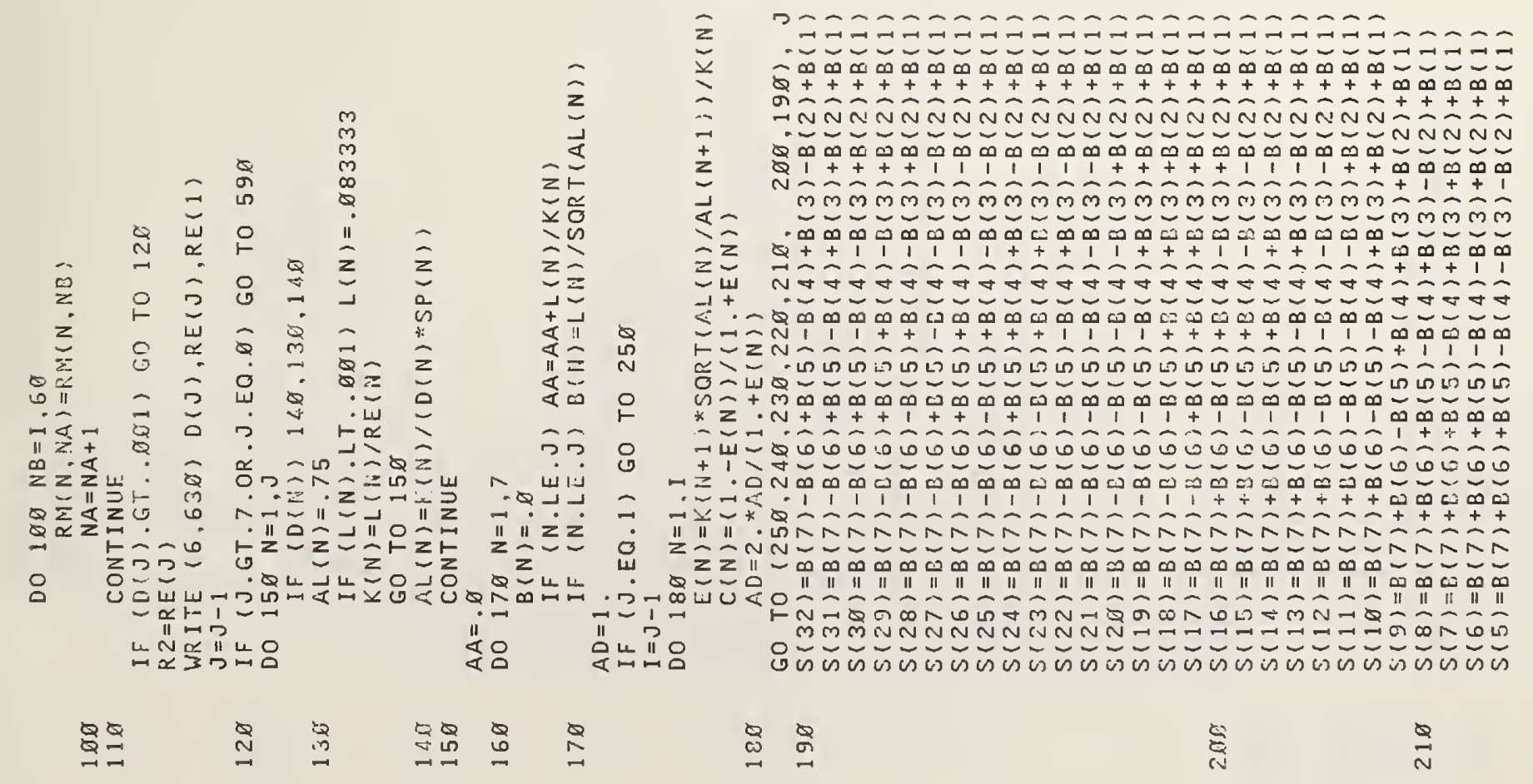


ニニニニニ

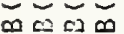

$+i$

NNNN

का

$+11 !$

लेलेल

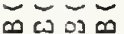

11

合市卞

का山心

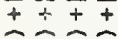

ถิำเป็น

क्ष我

$+i+t$

कीजि

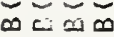

$+\infty+\frac{1}{+\infty}+$

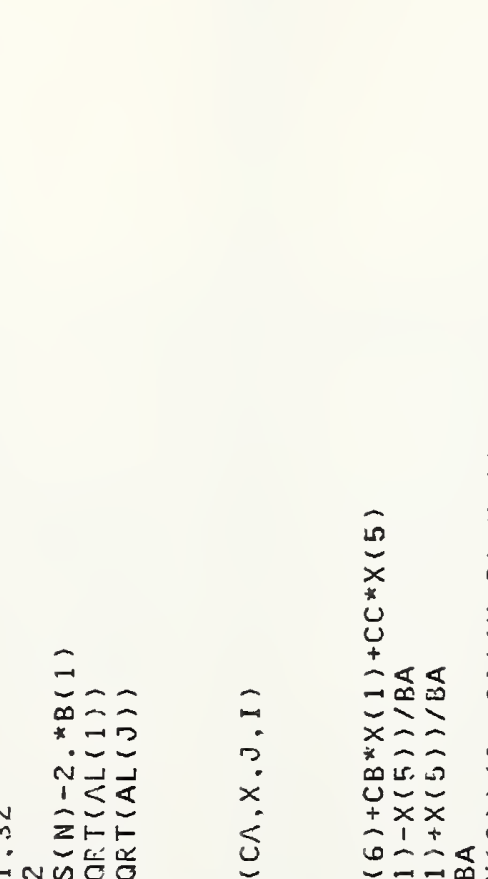

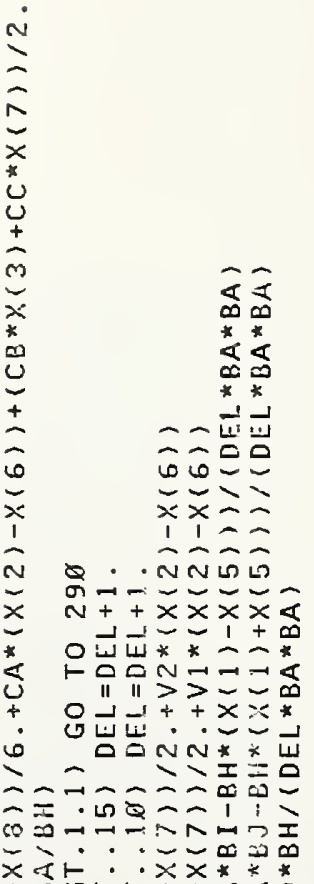

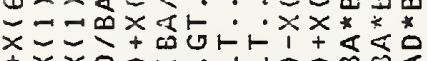

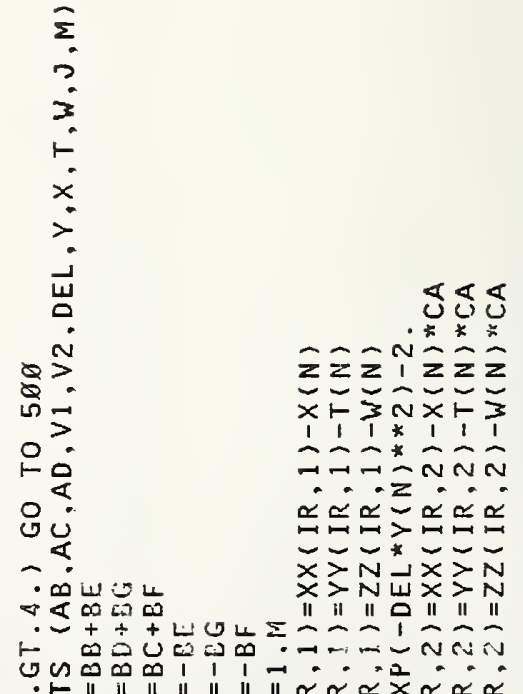

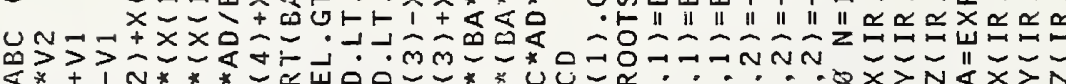

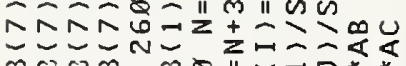

仙 "II $\|$ II ** TNN 的的的星的星

$\sum_{\substack{1 \\ \hdashline}}^{\mathbb{1}}$ $Q Q Q$ $-\geq \| 1111$

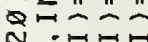
N・ロロロ > m. $N \mathrm{~N} N \mathrm{~N} N$ 


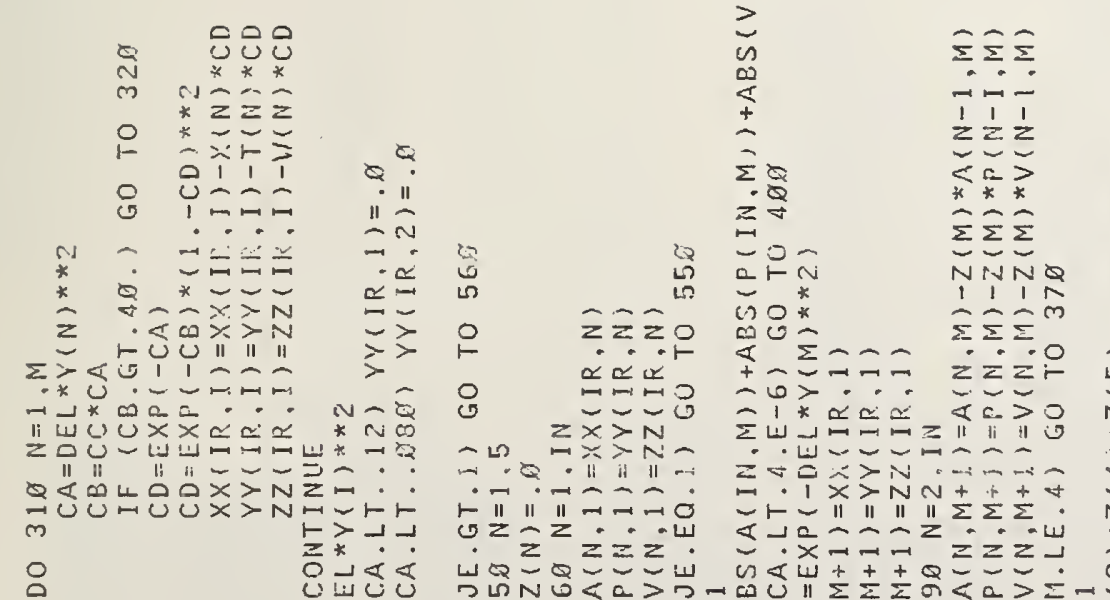

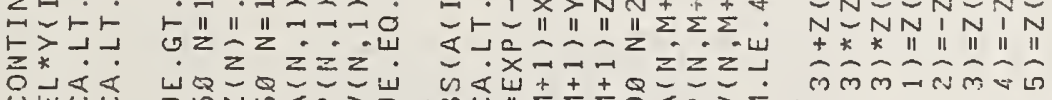

Zm m<a>

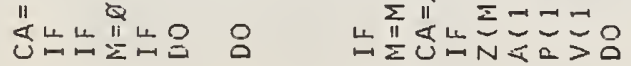

L

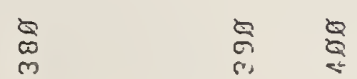

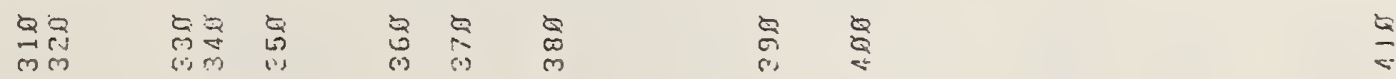




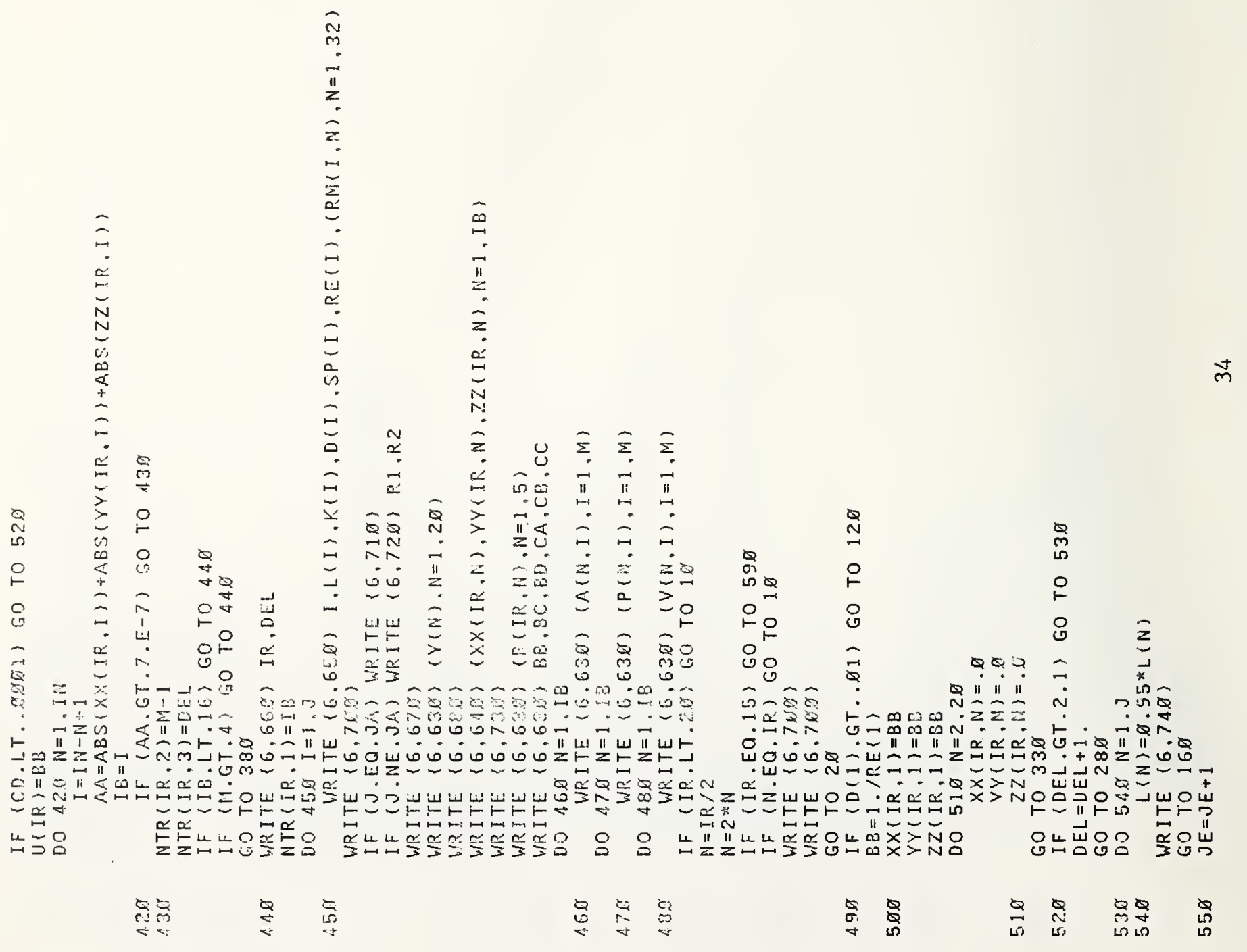

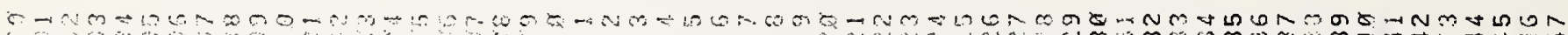

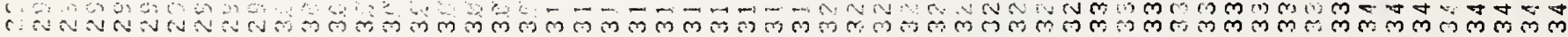




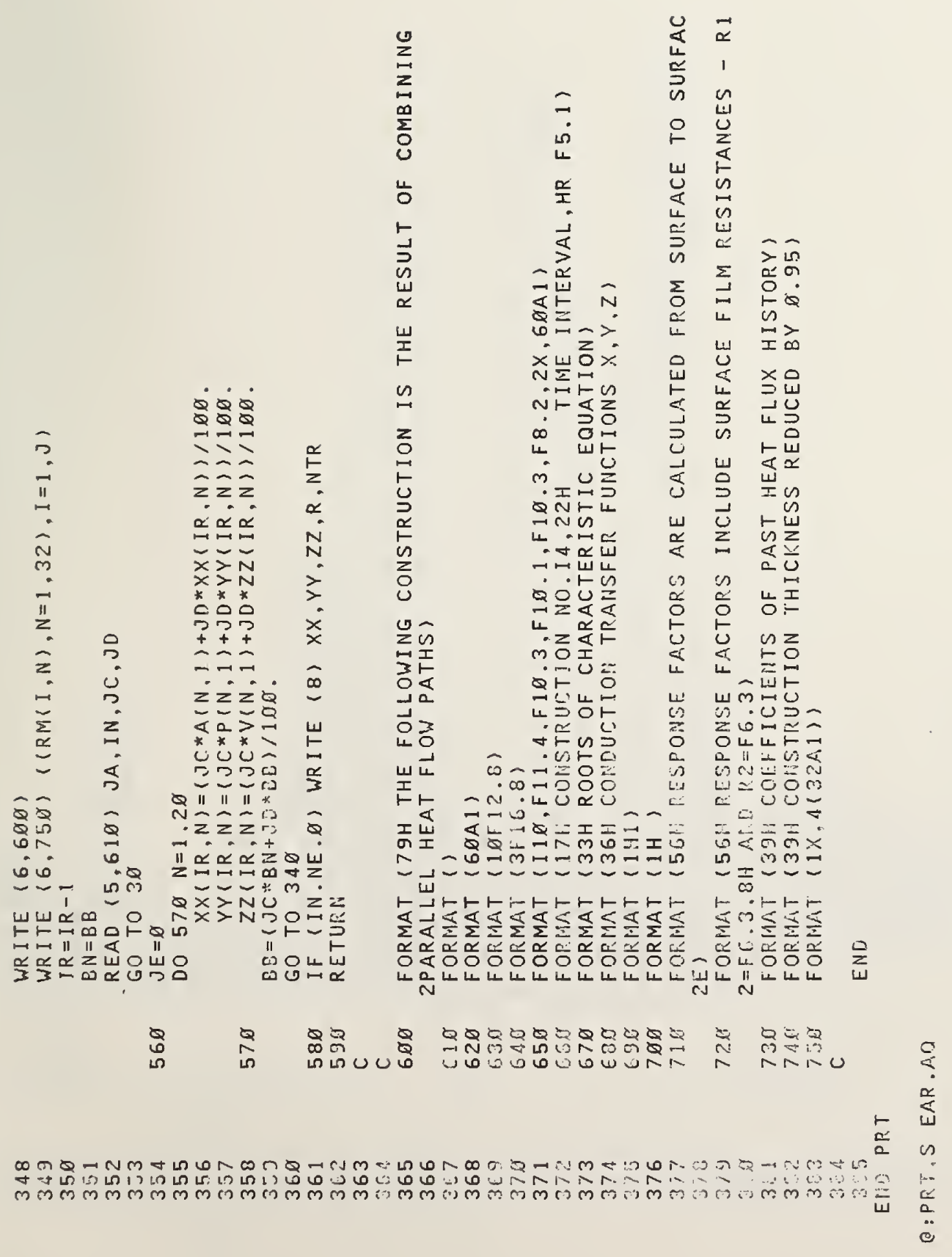




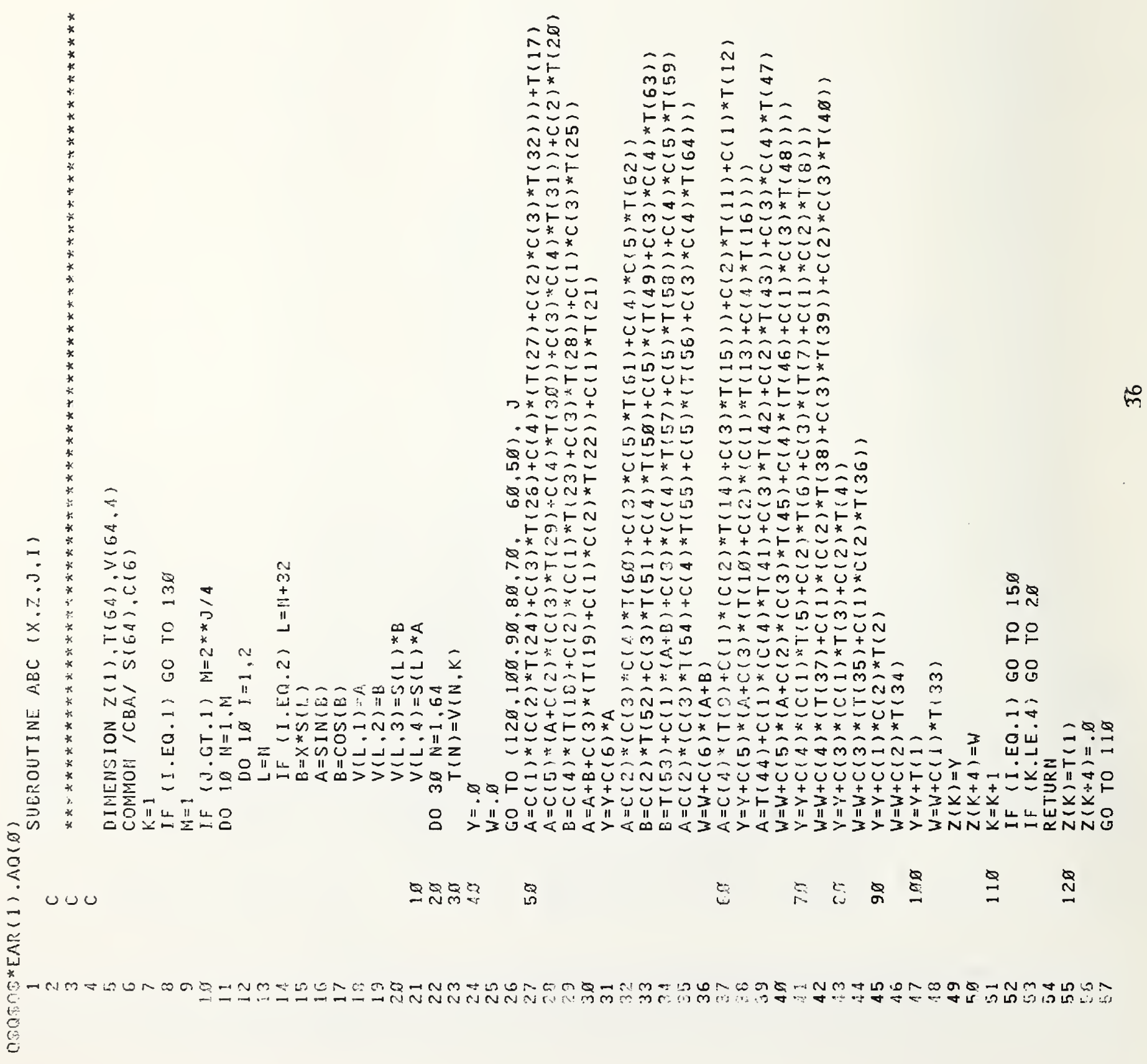




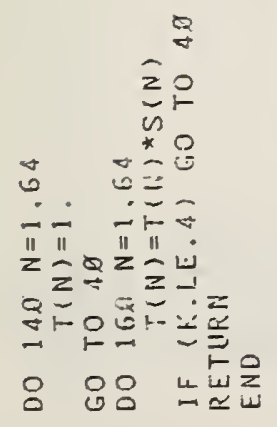

点造

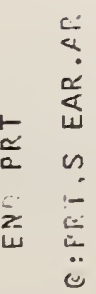




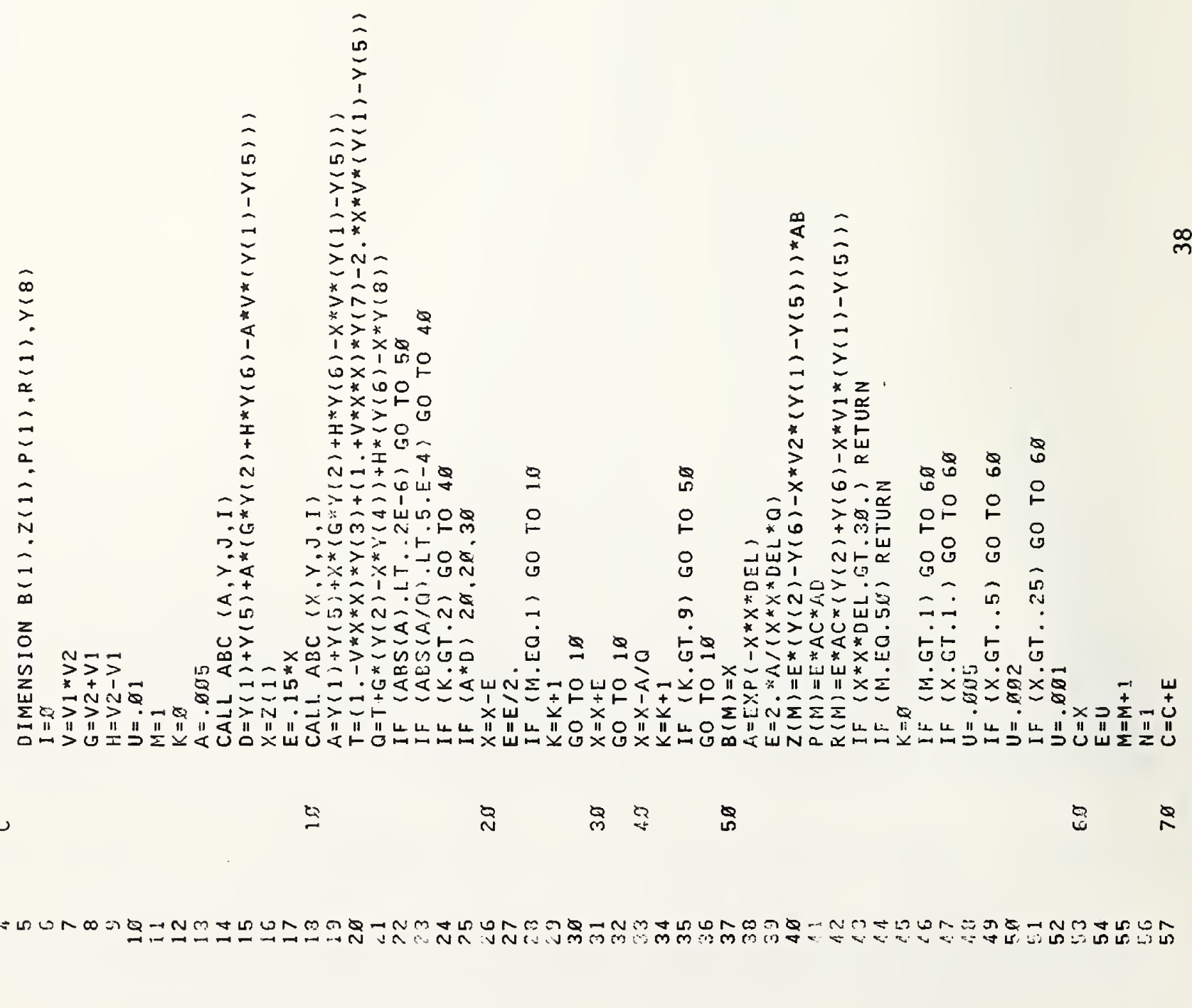


$\underset{-\infty}{Q \infty}$

안안

옹

$\widehat{乛} \widehat{Q}$

$3=5 \div$

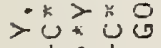

نェú

는ำ

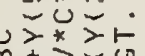

年

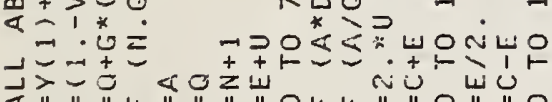

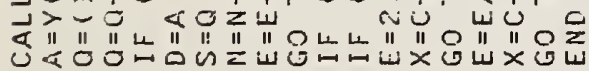

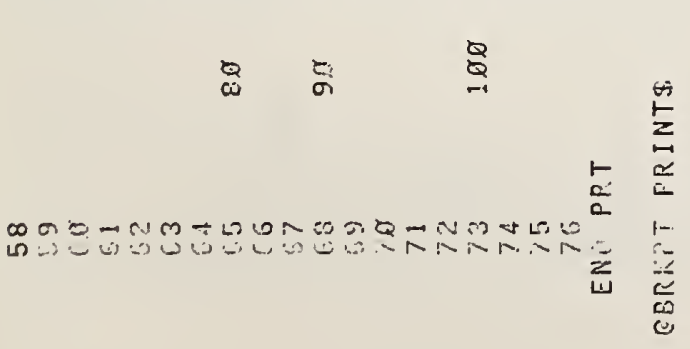




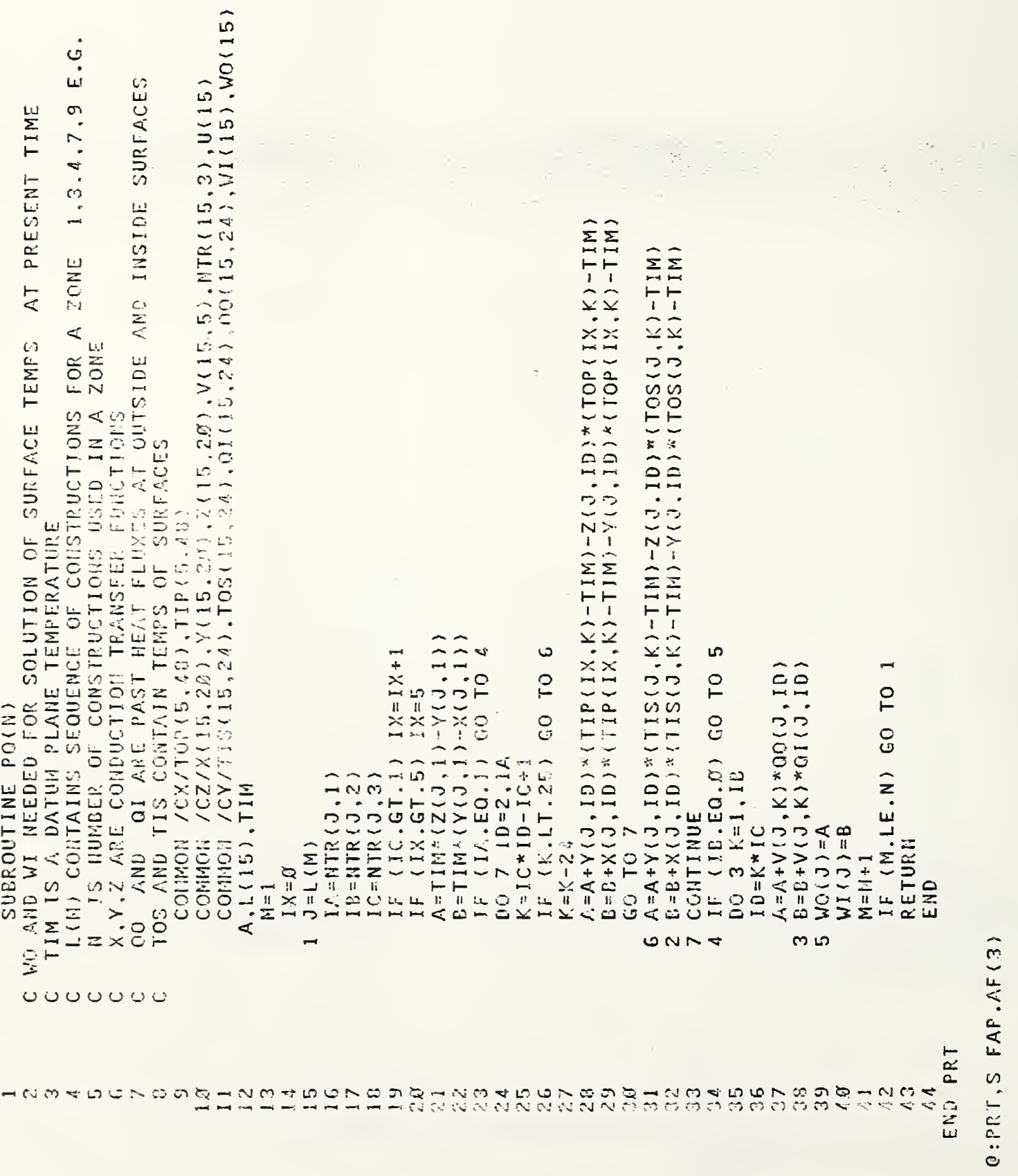

악 
$\begin{array}{ll} & \\ 0 & \end{array}$

马

艾沶:

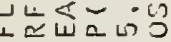

至ニニ?

एक

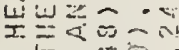

a. $\cos \cdot \cos 50$

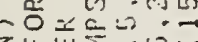

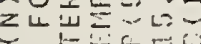

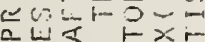

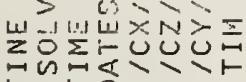

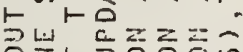

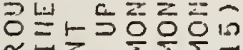

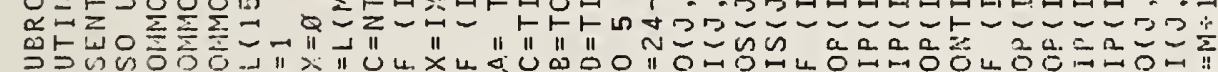

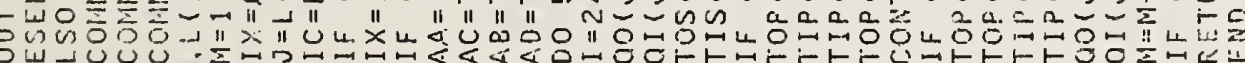

क

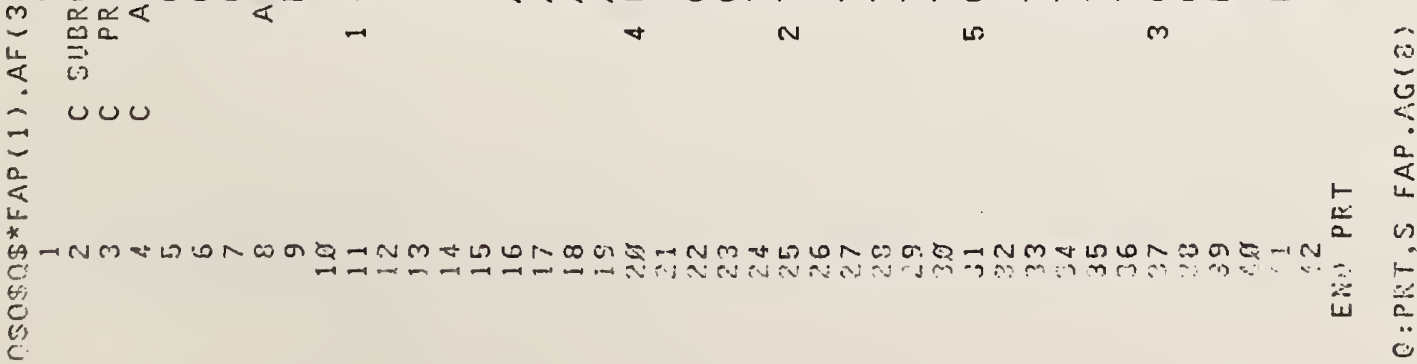

-

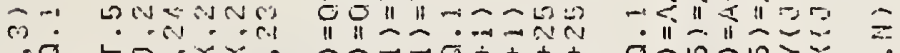

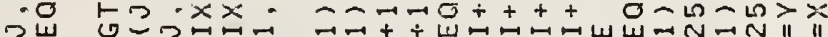

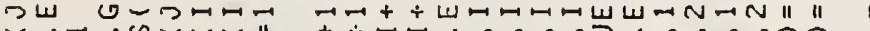

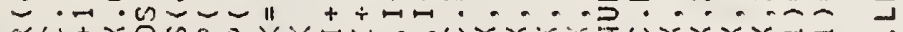
a $U+>0$ n

안 $n \quad$ = - 


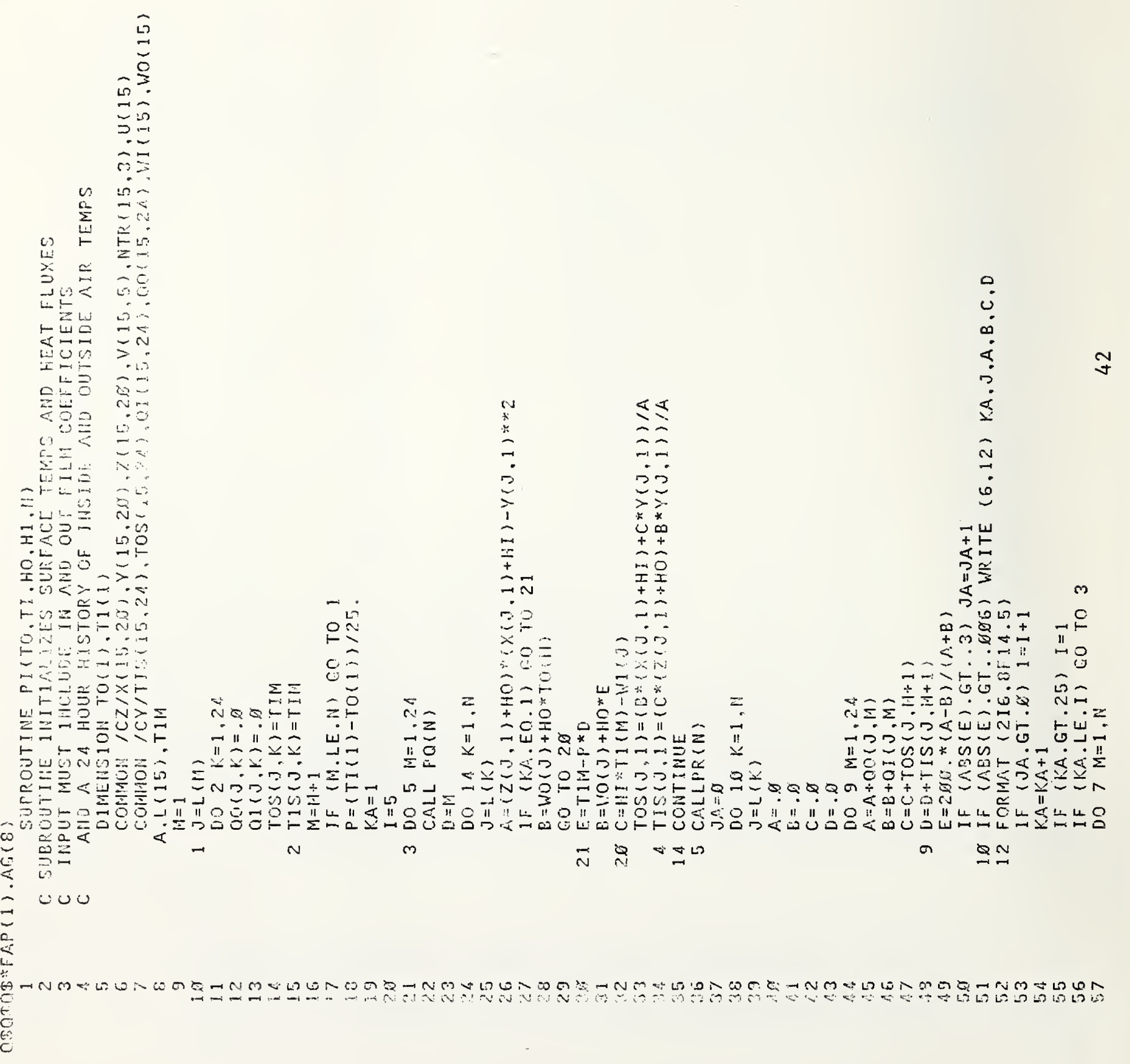




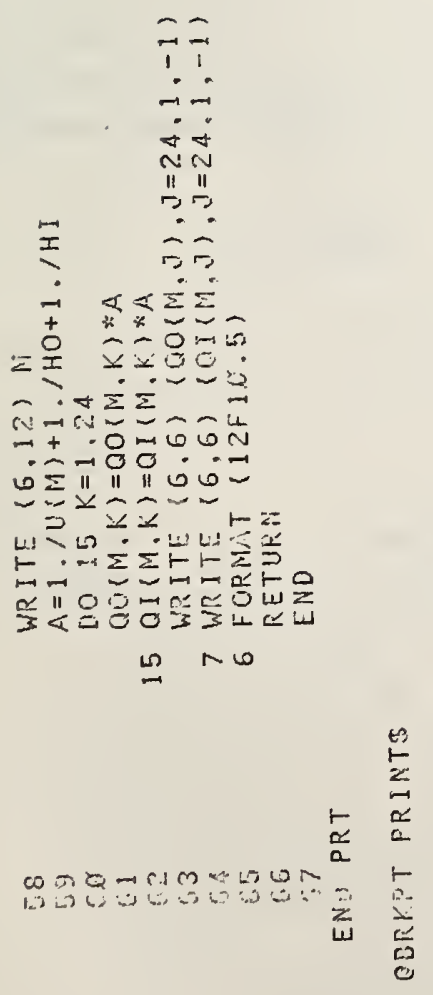




\section{FEDERAL INFORMATION PROCESSING STANDARD SOFTWARE SUMMARY}

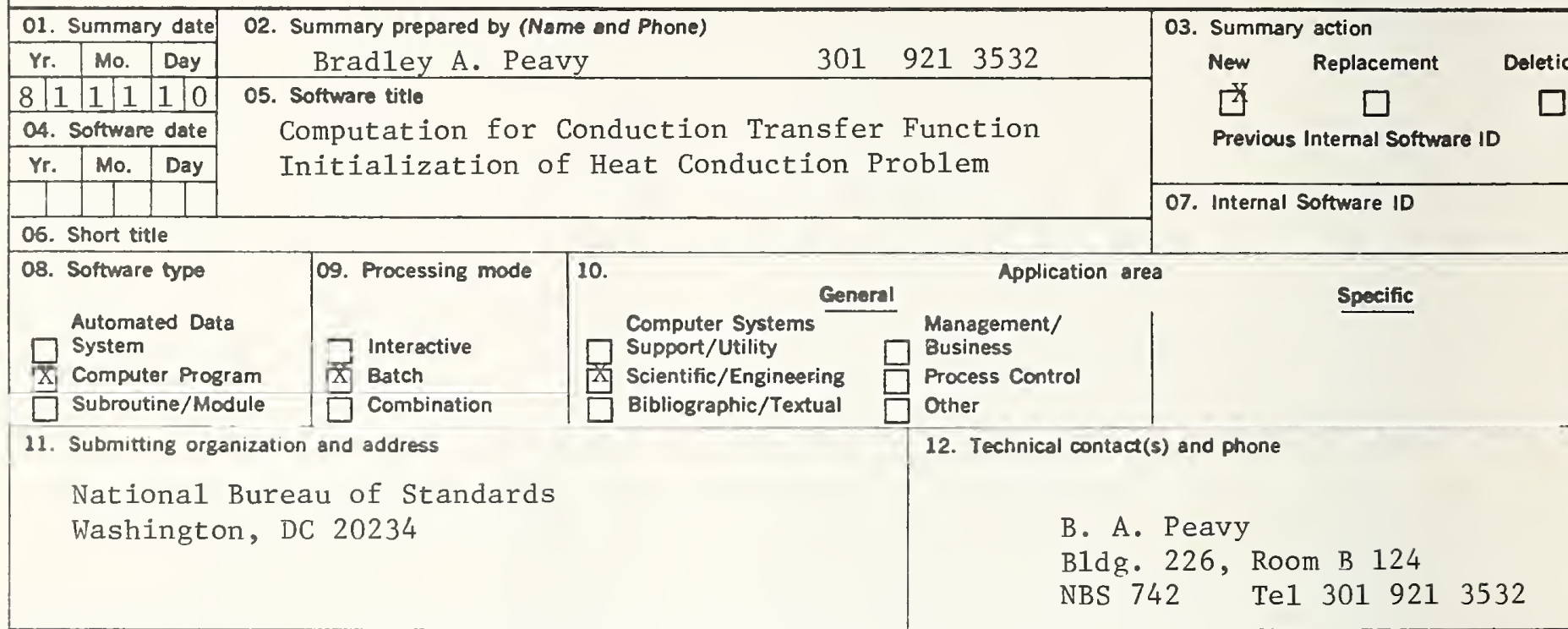

13. Narrative

Program (subroutine PC) computer conduction transfer functions of multi-layer building constructions for thermal conduction applications. Provision is made for including or excluding surface film thermal resistances, for the combination of two building constructions acting as parallel heat flow paths, and for the use of 1-, 2-, or 3-hour time intervals, depending on the thickness of the building construction. Subroutine PC may be easily modified to accommodate any time interval necessary.

Subroutines PI, PQ, and PR are included to define the initialization of the heat con-. duction from an initial datum plane temperature to a steady periodic condition. The subroutines use conduction transfer functions from subroutine PC, the inside and outside surface film coefficient, and a 24-hour history of inside and outside air temperatures. The inside and outside surface temperatures are found from the heat balances at the surfaces.

14. Key words: conduction heat transfer; conduction transfer functions; initialization of heat transfer problem; parallel heat flow; response factors; thick building construction.

\begin{tabular}{|l|l|l|l|}
\hline $\begin{array}{l}\text { 15. Computer manuf'r and model } \\
\text { UNIVAC } 1108\end{array}$ & $\begin{array}{c}\text { 16. Computer operating system } \\
\text { Time sharing system }\end{array}$ & $\begin{array}{c}\text { 17. Programing language(s) } \\
\text { FORTRAN V }\end{array}$ & $\begin{array}{c}\text { 18. Numer of source program state- } \\
\text { ments }\end{array}$ \\
\hline 19. Computer memory requirements & $\begin{array}{c}\text { 20. Tape drives } \\
\text { None }\end{array}$ & $\begin{array}{c}\text { 21. Disk/Drum units } \\
\text { None }\end{array}$ & 22. Terminals \\
\hline
\end{tabular}

23. Other operational requirements

24. Software availability Available

Q
Limited

$\square$
In-house only

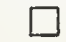

25. Documentation availability

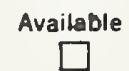

Inadequate
In-house only

26. FOR SUBMITIING ORGANIZATION USE 
NBS-114A (REV. 2-8C)

U.S. DEPT. OF COMM.

1. PUBLICATION OR REPORT NO.

BIBLIOGRAPHIC DATA

SHEET (See instructions)

NBSIR 812353

2. Performing Organ. Report No.

3. Publication Date

November 1981

4. TITLE AND SUBTITLE

DOCUMENTATION OF PROGRAM FOR DETERMINATION OF HEAT CONDUCTION TRANSFER FUNCTIONS

5. AUTHOR(S)

Bradley A. Peavy

6. PERFORMING ORGANIZATION (If joint or other thon NBS, see instructions)

7. Contract/Grant No.

NATIONAL BUREAU OF STANDARDS

DEPARTMENT OF COMMERCE

8. Type of Report \& Period Covered

WASHINGTON, D.C. 20234

9. SPONSORING ORGANIZATION NAME AND COMPLETE ADDRESS (Street, City, State, ZIP)

10. SUPPLEMENTARY NOTES

[] Document describes a computer program; SF-185, FIPS Software Summary, is attached.

11. ABSTRACT (A 200-word or less foctual summary of most significant information. If document includes o significant bibliography or literoture survey. mention it here)

Conduction transfer functions are used to predict the time-dependent one-dimensional conduction heat transfer at surfaces of single- or multi-layer building constructions based on heat flux and temperature history at each surface. By the use of conduction transfer functions, heat transfer problems employing non-linear boundary conditions such as thermal radiation and time-dependent changes in the surface film resistances can be solved.

Because conduction transfer functions are analytically derived with an initial time condition of zero temperature potential throughout the solid materials, it becomes necessary to initialize the computation by including exposure to a number of outdoor weather cycles such that satisfactory initial conditions of temperature and heat flux exist at the inside and outside surfaces.

The program is set up for the use of 1-, 2-, or 3-hour time intervals, depending on the thickness of the building construction. The program allows for the combination of two building constructions, e.g., the parallel heat flow paths found in wood-frame walls.

12. KEY WORDS (Six to twelve entries; alphabetical order; capitalize only proper names; and separate key words by semicolons) conduction heat transfer; conduction transfer functions; initialization of heat transfer problem; parallel heat flow; response factors; thick building construction.

13. AVAILABILITY

XX Unlimited

For Official Distribution. Do Not Release to NTIS

Order From Superintendent of Documents, U.S. Government Printing Office, Washington, D.C. 20402.

14. NO. OF

PRINTED PAGES

47

XX Order From National Technical Information Service (NTIS), Springfield, VA. 2216I

$\$ 6.50$ 

